\title{
A new species of the odorous frog genus Odorrana (Amphibia, Anura, Ranidae) from southwestern China
}

\author{
Shize Li ${ }^{1,2}$, Ning Xu ${ }^{1}$, Jingcai Lv ${ }^{3}$, Jianping Jiang ${ }^{2}$, Gang Wei $^{4}$, Bin Wang ${ }^{\text {Corresp. } 2}$ \\ 1 Department of Food Science and Engineering, Maotai University, Renhuai, Guizhou, China \\ 2 CAS Key Laboratory of Mountain Ecological Restoration and Bioresource Utilization \& Ecological Restoration and Biodiversity Conservation Key \\ Laboratory of Sichuan Province, Chengdu Institute of Biology, Chinese Academy of Sciences, Chengdu, Sichuan, China \\ 3 Guizhou Institute of Biology, Guizhou Academy of Sciences, Guiyang, Guizhou, China \\ 4 Biodiversity Conservation Key Laboratory, Guiyang College, Guiyang, Guizhou, China \\ Corresponding Author: Bin Wang \\ Email address: wangbin@cib.ac.cn
}

The genus Odorrana is widely distributed in the mountains of East and Southeastern Asia. An increasing number of new species in the genus have been recognized especially in the last decade. Phylogenetic studies of the $O$. schmackeri species complex with wide distributional range also revealed several cryptic species. Here, we describe a new species in the species complex from Guizhou Province of China. Phylogenetic analyses based on mitochondrial DNA indicated the new species as a monophyly clustered into the Odorrana clade and sister to O. schmackeri, and nuclear DNA also indicated it as an independent lineage separated from its related species. Morphologically, the new species can be distinguished from its congeners based on a combination of the following characters: (1) having smaller body size in males (snout-vent length $<43.3 \mathrm{~mm}$ ); (2) head longer than wide; (3) dorsolateral folds absent; (4) tympanum of males large and distinct, tympanum diameter twice as long as width of distal phalanx of finger III; (5) two metacarpal tubercles; (6) relative finger lengths: II $<$ I $<$ IV $<$ III; (7) tibio-tarsal articulation reaching to the level between eye to nostril when leg stretched forward; (8) disks on digits with circum-marginal grooves; (9) toes fully webbed to disks; (10) the first subarticular tubercle on fingers weak; (11) having white pectoral spinules, paired subgular vocal sacs located at corners of throat, light yellow nuptial pad on the first finger in males. 


\section{A new species of the odorous frog genus Odorrana (Amphibia, Anura, Ranidae) from southwestern China}

3

4

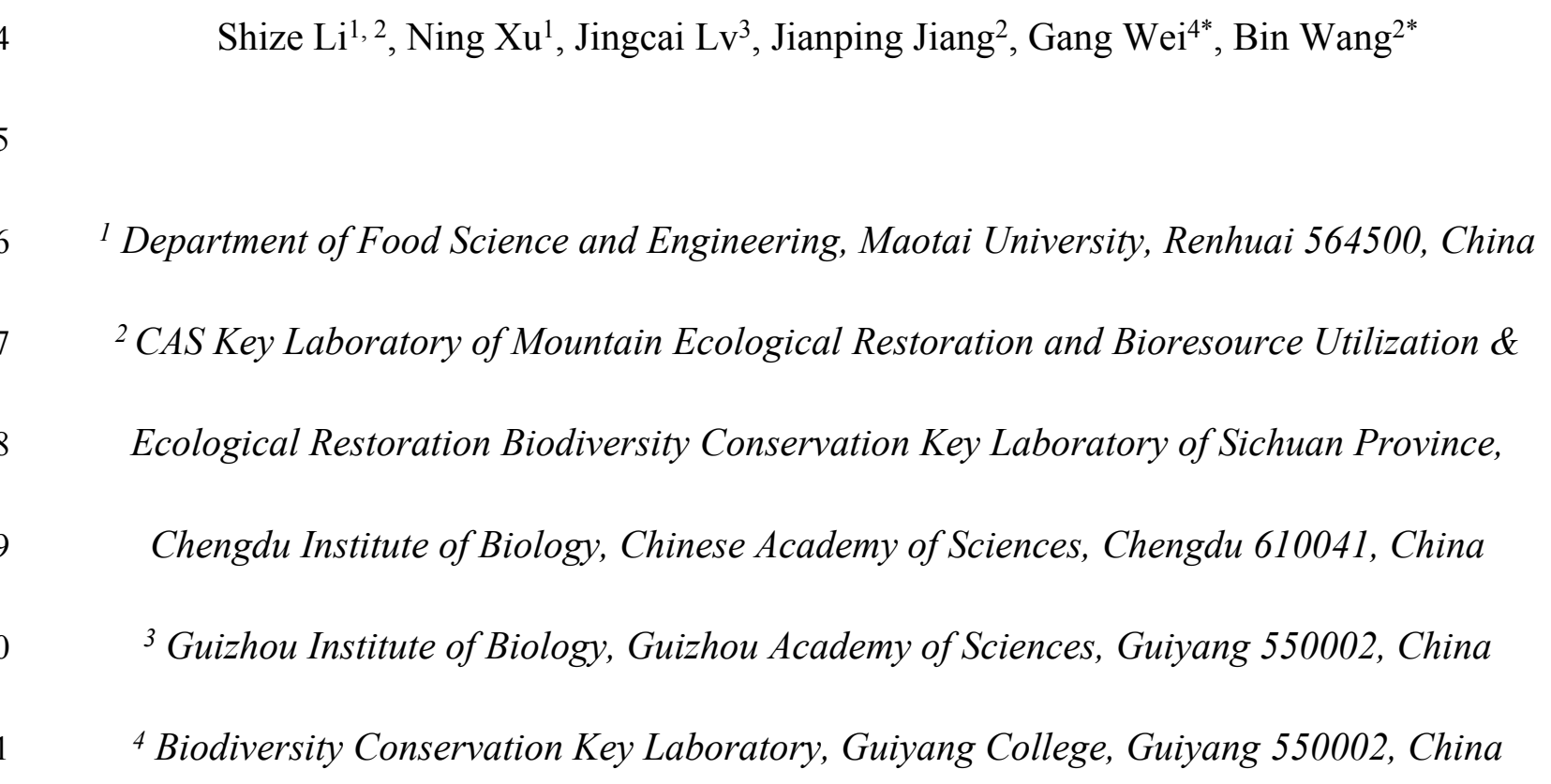

${ }^{1}$ Department of Food Science and Engineering, Maotai University, Renhuai 564500, China

${ }^{2}$ CAS Key Laboratory of Mountain Ecological Restoration and Bioresource Utilization \& Ecological Restoration Biodiversity Conservation Key Laboratory of Sichuan Province, Chengdu Institute of Biology, Chinese Academy of Sciences, Chengdu 610041, China

${ }^{4}$ Biodiversity Conservation Key Laboratory, Guiyang College, Guiyang 550002, China

0

*Correspondence: Bin Wang, e-mail: wangbin@cib.ac.cn; Gang Wei, e-mail:

wg198553@126.com.

\section{ABSTRACT}

21 The genus Odorrana is widely distributed in the mountains of East and Southeastern Asia. An increasing 
number of new species in the genus have been recognized especially in the last decade. Phylogenetic studies of the $O$. schmackeri species complex with wide distributional range also revealed several cryptic species. Here, we describe a new species in the species complex from Guizhou Province of China. Phylogenetic analyses based on mitochondrial DNA indicated the new species as a monophyly clustered into the Odorrana clade and sister to O. schmackeri, and nuclear DNA also indicated it as an independent lineage separated from its related species. Morphologically, the new species can be distinguished from its congeners based on a combination of the following characters: (1) having smaller body size in males (snout-vent length $<43.3 \mathrm{~mm}$ ); (2) head longer than wide; (3) dorsolateral folds absent; (4) tympanum of males large and distinct, tympanum diameter twice as long as width of distal phalanx of finger III; (5) two metacarpal tubercles; (6) relative finger lengths: II $<$ I $<$ IV < III; (7) tibio-tarsal articulation reaching to the level between eye to nostril when leg stretched forward; (8) disks on digits with circum-marginal grooves; (9) toes fully webbed to disks; (10) the first subarticular tubercle on fingers weak; (11) having white pectoral spinules, paired subgular vocal sacs located at corners of throat, light yellow nuptial pad on the first finger in males.

INTRODUCTION

Frogs of the genus Odorrana Fei, Ye \& Huang, 1990 inhabit montane streams in the subtropical and 
43 China and Indochina, northeastern India, Myanmar and Malay Peninsula to Sumatra and Borneo (Frost, 2018).

Although the systematic relationships of the group had been controversial for decades, it has been recognized as a monophyly in recent years (e.g. Matsui et al., 2005; Ngo et al., 2006; Cai et al., 2007; Che et al., 2007; Stuart, 2008; Wiens et al., 2009; Pyron \& Wiens, 2011; Chen et al., 2013). The genus currently contains 58 recognized species (Frost, 2018). Noticeably, in the last decade, 13 species have been described (Li et al., 2008; Tran et al., 2008; Yang, 2008; Bain et al., 2009; Chen et al., 2010a, b; Kuramoto et al., 2011; Mo et al., 2015; Wang et al., 2015; Pham et al., 2016; Saikia et al., 2017). This indicated that the species diversity has been underestimated and more discoveries were obligatory in the genus.

The piebald odorous frog O. schmackeri was firstly found in Gaojiayan Town, Changyang County (Co.), Hubei Province (Prov.), China, and named by Boettger (1892) only based on one male specimen and with a negligible description. Thus, Liu \& Hu (1961) redescribed O. schmackeri based on some specimens from Daba Mountains and Xiushan Co. in Chongqing City of China near to the type locality of the species, and presented the diagnosis characters for the species, such as having great circle brown spots on dorsa and the outer vocal sac below pharynx in males. Afterwards, based on mass of reports and investigations, the species has been suggested to be distributed in Henan, Shaanxi, Gansu, Sichuan, Guizhou, Hubei, Anhui, Jiangsu, Zhejiang, Hunan, Guangdong and Guangxi provinces of China (Fei et al., 2009, 2012), even northern Thailand (Chanard, 2003) and northern Vietnam (Orlov et al., 2002; Nguyen et al., 2005). This group is highly adapted to mountain environments, inhabiting the moist evergreen broad-leaf forests and streams at 200-1400 m altitudes

(Fei et al., 2009). Accordingly, it could be assumed that the wide distributional range and strict habitat requirements might promote considerable divergence even speciation due to isolation in the group.

Correspondingly, populations ever classified as $O$. schmackeri were suggested to be much variable in 
morphology (Fei et al., 2009, 2012), indicating that there might be cryptic species in the group. Indeed, from this group, several new species have been constantly described: O. nanjiangensis Fei, Ye, and Jiang, 2007 occurring from Nanjiang County (Co.), Sichuan Province (Prov.); O. huanggangensis Chen, Zhou and Zheng, 2010a occurring from Wuyi Mountains in Fujian and Jiangxi provinces; and O. tianmuii Chen, Zhou and Zheng, 2010b occurring from Tianmu Mountains in Zhejiang Prov.. However, phylogenetic analyses of Chen et al. (2013) indicated that above four species did not form a monophyly, but were nested with some other Odorrana species including two cryptic species, and also strongly rejected the alliance of $O$. anlungensis, $O$. yizhangensis and $O$. lungshengensis with the $O$. schmacheri group that was defined based on morphological data (Fei et al., 2009). So the "O. schmackeri species complex" was defined referring to the species resembling O. schmackeri on morphology, such as $O$. nanjiangensis, O. huanggangensis, O.hejiangensis, O. tianmuii and several cryptic species (e.g. Li et al., 2015; Zhu, 2016; He, 2017).

Recently, many studies have paid attention to the phylogenetic relationships and diversification of the $O$. schmackeri species complex (e.g. Li et al., 2015; Zhu, 2016). Li et al. (2015) presented a phylogeographic framework for the species complex using 25 populations based on mitochondrial ND2 and two tRNA gene sequences, and proposed seven clades: Clade A was (O. huanggangensis + "O. yizhangensis" identified by them) from Wuyi Mountains in Fujian Prov., Nanling Mountains in the border of Guangdong and Hunan provinces and mountains in eastern Guizhou Prov.; Clade B was O. tianmuii occurring from Huangshan Mountains in Anhui Prov. and Tianmu Mountains in Zhejiang Prov.; Clade C was O. schmackeri sensu stricto occupying a more narrow distribution area in Funiu Mountains in Henan and northern Hunan provinces and Daba Mountains in Hubei Prov.; Clade D was proposed as a cryptic species from mountains in Jiangxi Prov.; 
cryptic species from Funiu Mountains in Henan Prov. and being sympatric with Clade C; and Clade G was the fourth cryptic species from Daba Mountains in Hubei Prov. and also being sympatric with $O$. schmackeri sensu stricto (Fig. 1). As well, Zhu (2016) based on 12S rRNA and 16S rRNA genes showed a broadly similar phylogeographic framework through a more comprehensive sampling with 78 populations, and supplied several different implications: Clade D in Li et al. (2015) should not be recognized as a cryptic species but still be classified as $O$. schmackeri, and thus $O$. schmackeri sensu stricto was in fact distributed in western Henan, southeastern Shanan'xi, eastern to central Chongqing, northwestern and eastern Hubei, northwestern Hunan, northeastern Guizhou and Jiangxi provinces in China; $O$. hejiangensis occupied a large range around Sichuan Basin even in western Henan and eastern Shananxi provinces; one cryptic species (Odorrana sp1 defined by them) had a large range across central Guizhou and Guangxi provinces; and another cryptic species (Odorrana sp2 defined by them) occupied a large range around the southern part of Sichuan Basin (Fig. 1). However, because of different samplings and use of different genes in the two studies especially Li et al. (2015) having no morphological data and no releasing of sequences in Zhu (2016), there were still several uncertain points: (1) whether Clade E in Li et al. (2015) containing only two populations (Jinsha Co. and Suiyang Co. in Guizhou Prov.) belonged to Odorrana sp1 in Zhu (2016); (2) whether Clade F (the third cryptic species) from Funiu Mountains in Henan Prov. in Li et al. (2015) belonged to O. hejiangensis; (3) whether Clade G from Daba Mountains in Li et al. (2015) belonged to Odorrana sp2 in Zhu (2016). Anyway, several cryptic species in the species complex have been indicated. To better understand diversification of the species complex, it is necessary and urgent to make more investigations (e.g. distribution range, morphology, molecular phylogenetics, ecology and tadpoles) on the new taxa.

From 2013 to 2017, we carried out a series of biodiversity surveys in Guizhou Prov. of China and 
106

107

108

109

110

111

112

113

114

115

116

117

118

119

120

121

122

123

124

125

126

12

collected many specimens of Odorrana superficially resembling $O$. schmackeri. As note, some of them were collected from the population in the Lengshuihe Reserve in Jinsha Co., Guizhou Prov., China (Fig. 1) where the samples of Clade E in Li et al. (2015) indicated as a cryptic species was collected. To distinguish these specimens, we conducted phylogenetic analyses based on mitochondrial DNA and nuclear DNA and morphological comparisons. All analyses consistently supported our specimens from Guizhou Prov. as a new taxon. Hence, we describe it herein as a new species.

\section{METHODS}

\section{Sampling}

5 Frogs were collected on September 17 and 21, 2013 and August 3, 4 and 8, 2015, and tadpoles were collected on October 10, 2017. After taking photographs, they were euthanized using isoflurane, and then the specimens were fixed in $10 \%$ buffered formalin. Tissue samples were taken and preserved separately in $95 \%$ ethanol prior to fixation. Specimens collected in this work were deposited in Chengdu Institute of Biology,

\section{Chinese Academy of Sciences (CIB, CAS).}

A total of 25 adult specimens of the new taxon including 16 females and nine males were collected from the mountain streams of three localities across Guizhou Province of China (Fig. 1; for voucher information see Table S1). For comparisons, some specimens of the related species were also collected in this study, including 19 O. schmackeri specimens from two localities, 23 O. huanggangensis specimens from three localities, three O. yizhangensis specimens from two localities and two O. lungshengensis specimens from one locality (Fig. 1; for voucher information see Table S1).

26 Ten tadpoles with almost identical morphology were collected from the same place in the stream where 
the new taxon was found in the Lengshuihe Nature Reserve of Jinsha Co., Guizhou Prov., China. They were

identified as the new taxon because they were almost identical in morphology and one representative of them

was genetically close to the adult specimens of the new taxon (see the results). Stages of tadpoles were

identified following Gosner (1960).

\section{Collection of molecular data}

A total of 18 molecular samples were collected in this study: five containing four adults and one tadpole of

the new taxon, five of $O$. schmackeri including two topotypes, three of $O$. huanggangensis, three of $O$.

yizhangensis including one topotype, and two of $O$. lungshengensis (for voucher information see Table S2).

Total DNA was extracted using a standard phenol-chloroform extraction protocol (Sambrook et al., 1989).

The mitochondrial 12S rRNA, 16S rRNA and ND2 genes and two nuclear protein-coding genes (DOLK and

KCNF genes) were amplified and sequenced from our samples. Primer sequences were acquired from

literatures for 12S rRNA (Kocher et al., 1989), 16S rRNA (Simon et al., 1994), ND2 (Li et al., 2015), DOLK

(Shen et al., 2013) and KCNF (Shen et al., 2013) genes (primer sequences were presented in Table S3). PCR

amplification reactions for mitochondrial genes were performed in a $30 \mu \mathrm{L}$ volume reaction with the following

cycling conditions: an initial denaturing step at $95{ }^{\circ} \mathrm{C}$ for $4 \mathrm{~min} ; 36$ cycles of denaturing at $95{ }^{\circ} \mathrm{C}$ for $40 \mathrm{~s}$,

annealing at $55^{\circ} \mathrm{C}$ (for $12 \mathrm{~S}$ and $16 \mathrm{~S}$ ) $/ 47^{\circ} \mathrm{C}-57^{\circ} \mathrm{C}$ (for ND2) for $40 \mathrm{~s}$ and extending at $72{ }^{\circ} \mathrm{C}$ for $70 \mathrm{~s}$, and a

final extending step of $72{ }^{\circ} \mathrm{C}$ for $10 \mathrm{~min}$. Amplifications of nuclear genes were according to Shen et al. (2013).

PCR products were purified with spin columns and then were sequenced with both forward and reverse

primers same as used in PCR. Sequencing was conducted using an ABI3730 automated DNA sequencer in 
For phylogenetic analyses, we downloaded $12 \mathrm{~S}$ and $16 \mathrm{~S}$ gene sequences from GenBank for all those

149

150

151

152

153

154

155

156

157

158

159

160

161

162

163

164

165

166

167

168

related species especially for their topotypes for which comparable sequences were available (for GenBank

Accession numbers see Table S2) based on the previous studies (Chen et al., 2013; Li et al., 2015). As note,

ND2 gene sequences for most Odorrana species were not sequenced to now, impeding us to examine

comprehensive relationships of the genus using this gene. To further understand the divergence between the

new taxon and its related species, ND2 sequences for all haplotypes of the $O$. schmackeri species complex in

Li et al. (2015) were downloaded (for GenBank Accession number see Table S2).

\section{Phylogenetic analyses and genetic distance estimation}

Sequences were assembled and aligned using the ClustalW module in BioEdit v. 7.0.9.0 (Hall, 1999) with

default settings. The datasets were checked by eye and revised manually if necessary. To avoid bias in

alignments, GBLOCKS v. 0.91.b (Castresana, 2000) with default settings was used to extract regions of

defined sequence conservation from the length-variable $12 \mathrm{~S}$ and $16 \mathrm{~S}$ fragments. No-sequenced fragments were

treated as missing data. At last, for phylogenetic analyses of mitochondrial DNA, two datasets were obtained,

i.e. three-genes concatenated dataset with $12 \mathrm{~S}$ (for 61 samples) $+16 \mathrm{~S}$ (for 61 samples) + ND2 (for 16 samples)

and ND2 gene alone dataset (for 112 samples).

Based on the three-genes concatenated dataset, phylogenetic analyses were conducted using maximum

likelihood (ML) and Bayesian Inference (BI) methods, implemented in PhyML v. 3.0 (Guindon et al., 2010)

and MrBayes v. 3.12 (Ronquist \& Huelsenbeck, 2003), respectively. One Rana chensinensis was chosen as

outgroup according to the previous studies (Pyron \& Wiens, 2011; Chen et al., 2013). To avoid under- or over-

parameterization (Lemmon \& Moriarty, 2004; McGuire et al., 2007), for the phylogenetic analyses, the best

partition scheme and the best evolutionary model for each partition were chosen using PARTITIONFINDER v. 
1.1.1 (Lanfear et al., 2012). In this analysis, 12S, 16S genes and each codon position of ND2 gene were defined and Bayesian Inference Criteria (BIC) was used. As a result, the analysis suggested that the best partition scheme is $12 \mathrm{~S}$ gene/16S gene/each codon position of ND2 gene, and selected $\mathrm{TrN}+\mathrm{I}+\mathrm{G}$ model as the best model for $12 \mathrm{~S}, 16 \mathrm{~S}$ and the second codon position of ND2 gene and $\mathrm{GTR}+\mathrm{I}+\mathrm{G}$ model as the best model for the other two codon position of ND2 gene. For the ML tree, branch supports were drawn from 10000 nonparametric bootstrap replicates. In BI analyses, the parameters for each partition were unlinked, and branch lengths were allowed to vary proportionately across partitions. Two runs each with four Markov chains were simultaneously run for 50 million generations with sampling every 1000 generations. The first $25 \%$ trees were removed as the "burn-in" stage followed by calculations of Bayesian posterior probabilities and the $50 \%$ majority-rule consensus of the post burn-in trees sampled at stationarity. members of the $O$. schmackeri species complex recognized by Li et al. (2015), a phylogenetic network using the maximum parsimony method in Splittree v. 4.11.3 (Huson \& Bryant, 2006) was constructed based on the

ND2 gene sequence dataset. The supports of Splittree lineages were evaluated by 1000 bootstrap replicates.

maximum parsimony method in TCS v. 1.21 (Clement et al., 2000).

Finally, pairwise uncorrected $p$-distance on the 16S rRNA gene were estimated using MEGA v. 6.06

(Tamura et al., 2011) to evaluate the genetic divergence between Odorrana species.

Morphological comparisons 
females of $O$. schmackeri and 13 males and ten females of $O$. huanggangensis were measured (for voucher information see Table S1). Ten tadpoles of the new taxon were measured (for voucher information see Table S4). The terminology and methods followed Fei et al. (2009). Measurements were taken with a dial caliper to the nearest $0.1 \mathrm{~mm}$. Twenty one morphometric characters of adult specimens were measured: SVL $=$ snoutvent length (distance from the tip of the snout to the posterior edge of the vent), HDL = head length (distance from the tip of the snout to the articulation of jaw), HDW = maximum head width (greatest width between the left and right articulations of jaw), $\mathrm{SL}=$ snout length (distance from the tip of the snout to the anterior corner of the eye), $\mathrm{ED}=$ eye diameter (distance from the anterior corner to the posterior corner of the eye), IOD = interorbital distance (minimum distance between the inner edges of the upper eyelids), IND = internasal distance (minimum distance between the inner margins of the external nares), NED = nasal to eye distance (distance between the nasal and the anterior corner of the eye), NSD = nasal to snout distance (distance between the nasal the posterior edge of the vent), IFE = distance between anterior corner of eyes, IAE $=$ distance between posterior corner of eyes, TYD = maximal tympanum diameter, $\mathrm{LAL}=$ length of lower arm and hand (distance from the elbow to the distal end of the Finger IV), LW = lower arm width (maximum width of the lower arm), THL = thigh length (distance from vent to knee), $\mathrm{TL}=$ tibia length (distance from knee to tarsus), $\mathrm{TW}=$ maximal tibia width, $\mathrm{TFL}=$ length of foot and tarsus (distance from the tibiotarsal articulation to the distal end of the Toe IV), FL = foot length (distance from tarsus to the tip of fourth toe), FDW = finger disk width (width at the widest part of the disk of finger III), DPW = distal phalanx width (maximal width of distal phalanx of finger III). Ten morphometric characters of larvae were measured: $\mathrm{TOL}=$ total length, $\mathrm{SVL}=$ snout-vent length, $\mathrm{BH}=$ maximum body height, $\mathrm{BW}=$ maximum body width, $\mathrm{SL}=$ snout length (distance from the anterior corner of the eye to the tip of the snout), $\mathrm{SS}=$ snout to spiraculum (distance from spiraculum 
211 to the tip of the snout), MW = mouth width (distance between two corners of mouth), TBW = maximum width

212 of tail base, $\mathrm{TL}=$ tail length (distance from base of vent to the tip of tail), $\mathrm{TH}=$ tail height (maximum height

213 between upper and lower edges of tail).

214 In order to reduce the impact of allometry, the correct value from the ratio of each measurement to SVL

215 was calculated and then log-transformed for the following morphometric analyses. One-way analysis of

variance (ANOVA) was used to test the significance of differences on morphometric characters between males

and females and between different species. The significance level was set at 0.05 . To show the spatial

distribution of different species on the morphometric characters, principal component analyses (PCA) were

performed. These analyses were carried out in the R (R Development Core Team, 2008).

The new species was also compared with all other Odorrana species on morphology. Comparative

morphological data were obtained from literatures for O. absita (Stuart \& Chan-ard, 2005), O. amamiensis

(Matsui, 1994), O. andersonii (Boulenger, 1882), O. anlungensis (Hu et al., 1973), O. arunachalensis (Saikia

et al., 2017), O. aureola (Stuart et al., 2006), O. bacboensis (Bain et al., 2003), O. banaorum (Bain et al.,

2003), O. bolavensis (Stuart \& Bain, 2005), O. cangyuanensis (Yang, 2008), O. chapaensis (Bourret, 1937$),$ O.

chloronota (Günther, 1876), O. exiliversabilis (Li et al., 2001 in Fei et al., 2001b), O. fengkaiensis (Wang et al.,

2015), O. geminata (Bain et al., 2009), O. gigatympana (Orlov et al., 2006), O. grahami (Boulenger, 1917 ), O.

graminea (Boulenger, 1900), O. hainanensis (Fei et al., 2001a), O. hejiangensis (Deng \&Yu, 1992), O. hosii

(Boulenger, 1891), O. huanggangensis (Chen et al., 2010a), O. heatwolei (Stuart \& Bain, 2005), O.

hmongorum (Bain et al., 2003), O. indeprensa (Bain \& Stuart, 2005), O. ishikawae (Stejneger, 1901$)$, O.

jingdongensis (Fei et al., 2001a), O. junlianensis (Fei \& Ye, 2001 in Ye and Fei, 2001), O. khalam (Stuart et 
232 lipuensis (Mo et al., 2015), O livida (Blyth, 1856), O. macrotympana (Yang, 2008), O. margaretae (Liu, 1950),

233 O. mawphlangensis (Pillai \& Chanda, 1977), O. monjerai (Matsui \& Jaafar, 2005), O. morafkai (Bain et al.,

234 2003), O. mutschmanni (Pham et al., 2016), O. nanjiangensis (Fei et al., 2007a), O. narina (Stejneger, 1901),

235 O. nasica (Boulenger, 1903), O. nasuta (Li et al., 2001 in Fei et al., 2001b), O. orba (Stuart \& Bain, 2005), O.

236 rotodora (Yang \& Rao, 2008 in Yang, 2008), O. schmackeri (Boettger, 1892), O. sinica (Ahl, 1927), O.

splendida (Kuramoto et al., 2011), O. supranarina (Matsui, 1994), O. swinhoana (Boulenger, 1903), O.

tianmuii (Chen et al., 2010b), O. tiannanensis (Yang \& Li, 1980), O. tormota (Wu, 1977), O. trankieni (Orlov

et al., 2003), O. utsunomiyaorum (Matsui, 1994), O. versabilis (Liu \& Hu, 1962), O. wuchuanensis (Xu, 1983

in Wu et al., 1983), O. yentuensis (Tran et al., 2008), O. yizhangensis (Fei et al., 2007b) and O. zhaoi (Li et al., 2008).

Skull scanning

Skulls of two male specimens (voucher number: CIBjs20150803001, CIBjs20150803002) and three

female specimens (voucher number: CIBjs20150804001, CIBGYU20130917003, CIBGYU20130917001) of

the new taxon were scanned in the high-resolution X-ray scanner (Quantum GX micro-CT Imaging System,

PerkinElmer $\left.{ }^{\circledR}\right)$. The specimens were scanned along the coronal axis at an image resolution of $2000 * 2000$.

Segmentation and three-dimensional reconstruction of the CT images were made using VG57 Studio Max 2.2

(Volume Graphics, Heidelberg, Germany).

The Animal Care and Use Committee of Chengdu Institute of Biology, CAS provided full approval for

this purely observational research (Number: CIB2013041102). Field work was approved by the Management

Office of the Lengshuihe Nature Reserve (project number: LSH-201304003).

The electronic version of this article in Portable Document Format (PDF) will represent a published work 
253

254

256

according to the International Commission on Zoological Nomenclature (ICZN), and hence the new names contained in the electronic version are effectively published under that Code from the electronic edition alone.

This published work and the nomenclatural acts it contains have been registered in ZooBank, the online registration system for the ICZN. The ZooBank LSIDs (Life Science Identifiers) can be resolved and the associated information viewed through any standard web browser by appending the LSID to the prefix http://zoobank.org/. The LSID for this publication is: urn:lsid:zoobank.org:pub:E98B65CB-E8E3-4412-9613D9DD32A77B99. The online version of this work is archived and available from the following digital repositories: PeerJ, PubMed Central and CLOCKSS.

\section{RESULTS}

\section{Phylogenetic analyses and genetic divergence}

Aligned sequence matrix of 12S+16S, ND2, DOLK and KCNF genes contained 1835 bp, 768 bp, 645 bp and $750 \mathrm{bp}$, respectively. ML and $\mathrm{BI}$ analyses based on the $12 \mathrm{~S}+16 \mathrm{~S}+\mathrm{ND} 2$ matrix resulted in essentially identical topologies with high node supporting values (Fig. 2A). All samples of the new taxon occurring from Guizhou Prov. were strongly clustered into a monophyly, which was placed into the genus Odorrana and sister to the $O$. schmackeri clade. ND2 splitstree also strongly supported the splits between the new taxon and its related species (Fig. 2B). As note, Odorrana sp2 simultaneously revealed by Li et al. (2015) and Zhu (2016) and Odorrana sp3 revealed by Li et al. (2015) also occupied an independent lineage, respectively. Only one haplotype was found for all samples of the new taxon, either in KCNF gene or in DOLK gene, and there was no common haplotype between the new species and its related species (Fig. 3).

The genetic distances on $16 \mathrm{~S}$ gene between the new taxon and its sister species $O$. schmackeri was mean 
2740.027 (range 0.026-0.028; Table S5), much higher than the intraspecific genetic distance within each of the

275 new taxon, $O$. schmackeri, O. huanggangensis, O. yizhangensis and O. lungshengensis (all intraspecific

276 genetic distance $<0.002)$. More significantly, it was higher or even much higher than the interspecific genetic

277 distance between many sister species, for example, that between $O$. huanggangensis and $O$. tianmuii (0.014),

O. hainanensis and $O$. fengkaiensis (0.013), O. nasuta and O. versabilis (0.013), O. versabilis and $O$.

exiliversabilis (0.017), O. morafkai and O. banaorum (0.013), and O. grahami and O. jingdongensis $(0.017$;

Table S5).

281

282

283

\section{Morphological comparisons}

The results of one-way ANOVA showed that in the new taxon, the males was significantly different from the females on SVL and the ratios of ED, IND, IFE, LAL, TYD, LW and TW to SVL (all $p$-values $<0.05$;

Table 1). So, morphometric analyses were conducted on males and females, respectively. In PCA for males, the total variation of the first two principal components was $42.23 \%$, and in PCA for females, it is $37.37 \%$. In both males (Fig. 4A) and females (Fig. 4B), on the two-dimensional plots of PC1 versus PC2, the new taxon could be almost separated from $O$. schmackeri. The results of one-way ANOVA indicated that either in males or females, the new taxon was significantly different from $O$. schmackeri and $O$. huanggangensis on many morphometric characters (all $p$-values $<0.05$; Tables 1). More detailed descriptions of results from morphological comparisons between the new taxon and its congeners were presented in the following sections for describing the new species.

At all, molecular and morphological results supported that our specimens from Guizhou Prov. of China was a new taxon. It is described as a new species in the following sections:

Odorrana kweichowensis sp. nov. 
urn:1sid:zoobank.org:act:95123118-30D2-42B5-B5DB-AB7C32B33F97

\section{Holotype}

CIBjs20150803002, adult male (Fig. 5A and B; Fig. 6A and B), collected by S.Z. Li in the Lengshuihe Nature Reserve $\left(27.47361^{\circ} \mathrm{N}, 106.00139^{\circ} \mathrm{E}\right.$; elevation $754 \mathrm{~m}$ a.s.1.), Jinsha Co., Guizhou Prov., China.

\section{Paratypes}

24 specimens (nine adult males and 15 adult females), 14 specimens collected by S.Z. Li from the Lengshuihe

Nature Reserve in Jinsha Co., Guizhou Prov., China. Six males: CIBjs20150803001, CIBjs20150803003, CIBjs20150803004, CIBjs20150803005 collected on August 3, 2015 and CIBjs20150804002 on August 4, 2015; eight females: CIBjs20150803006, CIBjs20150803007, CIBjs20150803008 collected on August 3, 2015, CIBjs20150804001, CIBjs20150804003, CIBjs20150804004, CIBjs20150804005 on August 4, 2015 and CIBjs20150808020 on August 8, 2015. Seven specimens collected by S.Z. Li and J. C. Lv from Meitan Co. of Guizhou Prov., China. Three males: CIBGYU20130917004, CIBGYU20130917005 and CIBGYU20130917007 collected by J.C. Lv on September 17, 2013; four females: CIBGYU20130917001, CIBGYU20130917002 and CIBGYU20130917003 by S.Z. Li on September 17, 2013, CIBGYU20130917006 by J.C. Lv on September 17, 2013. Three females: GYU20130921001, CIBGYU20130921002 and CIBGYU20130921003 collected by S.Z. Li on September 21, 2013. Ten tadpoles (CIBjs20171014001CIBjs20171014010) collected by S.Z. Li on October 10, 2017.

\section{Diagnosis}

Odorrana kweichowensis sp. nov. is assigned to genus Odorrana based upon molecular phylogenetic analyses and the following morphological characters: dorsum is green; tips of digits dilated, tapering, disks with circum-marginal grooves, and vertical diameter longer than horizontal diameter in the disks; 
supernumerary tubercle below the base of fingers III and IV; feet fully webbed to disks, without tarsal fold; the

first finger thick and nuptial pad distinct.

Odorrana kweichowensis sp. nov. could be distinguished from its congeners by a combination of the

following characters: (1) having smaller body size in males (snout-vent length $<43.3 \mathrm{~mm}$ vs. snout-vent length $>$

$48 \mathrm{~mm}$ in many other species); (2) head longer than wider; (3) dorsolateral folds absent; (4) tympanum of

males large and distinct, tympanum diameter in males twice as long as width of distal phalanx of finger III; (5)

two metacarpal tubercles; (6) relative finger lengths: II $<$ I $<$ IV $<$ III; (7) tibiotarsal articulation reaching to the

level between eye to nostril when leg stretched forward; (8) disks on digits with circum-marginal grooves; (9)

toes fully webbed to disks; (10) the first subarticular tubercle on fingers weak; (11) having white pectoral

spinules, paired subgular vocal sacs located at corners of throat, light yellow nuptial pad on the first finger in

males.

327

328

329

\section{Description of holotype}

Head longer than wide $(\mathrm{HDL} / \mathrm{HDW}=1.08)$; top of head flat; snout obtusely rounded in dorsal view

$(\mathrm{SL} / \mathrm{HDL}=0.41)$, rounded in profile, projecting beyond lower jaw; eye large and convex, ED 0.83 times of SL;

$\mathrm{IND}=5.1 \mathrm{~mm}$, larger than $\mathrm{IOD}=3.2 \mathrm{~mm} ; \mathrm{NED}=3.4 \mathrm{~mm}$ larger than $\mathrm{NSD}=2.9 \mathrm{~mm}$; tympanum circular,

large and distinct, twice as long as width of distal phalanx of finger III (TYD/FDW = 2.84); vomerine teeth on well-developed ridges; tongue deeply notched posteriorly; paired gular pouches at corners of throat. Forelimbs moderately robust $(\mathrm{LW} / \mathrm{SVL}=0.11)$; lower arm and hand beyond a half of body length $(\mathrm{LAL} / \mathrm{SVL}=0.53)$; the first finger slightly longer than the second; finger tips on I-IV dilated to wide, tapering, disks with circummarginal grooves; nuptial pad on the inner of first finger from base to subarticular tubercles; subarticular tubercles relatively prominent; inner metacarpal tubercle oblong and outer metacarpal tubercle indistinct; no 
finger webbing.

Hindlimbs long; tibio-tarsal articulation reaching to the level between eye to nostril when hindlimb adpressed along the side of body; heels overlapping when hindlimbs positioned at right angle to body; singular longer than thigh length; FL 0.85 times SVL; toes slender, relative toe lengths: $\mathrm{I}<\mathrm{II}<\mathrm{III}<\mathrm{V}<\mathrm{IV}$; toes tapering dilated, disks with circum-marginal grooves; feet fully webbed to disks; web becoming narrower and continuing to the disks as lateral fringe on toes II, III and IV; outer metatarsal tubercle absent; inner metatarsal tubercle present.

Skin shagreened, a number of pustules scattered on dorsum of trunk and flanks; several irregular tubercles scattered on flanks; dorsolateral folds absent; two large glands on the place between below tympanum and above arm; white spinules on throat, chest, fore abdomen, inner side of forearms and upper and lower lips.

\section{Coloration in life}

In life, dorsum with bright green network ; large black spots in the center on dorsum, continuing onto dorsal portion of legs to form dark counter-point to bright green irregular bands; flank light yellow with several black spots; tympanum brown-black; upper and lower lip with vertical black bars; arms brown with black transverse bands, thighs with five brown bands and tibias with six (Fig. 6).

\section{Color in preservative}

On dorsum color fades to dark olive with dark brown blotches (Fig. 5A), upper and lower lips marbled brown-black on dirty white; venter variable from white to light yellow; underside of limbs yellowish with white (Fig. 5B); pinkish in the inner side of forearm and thighs; there is a white spot between front corner of eyes; nuptial pad fades to white (Fig. 5).

\section{Variation}


morphology and color pattern, but different from females. SVL in females approximately 1.8 times that in males (SVL mean $73.6 \mathrm{~mm}$, range $62.4-81.1 \mathrm{~mm}$ in females, SVL mean $41.0 \mathrm{~mm}$, range $36.2-43.3 \mathrm{~mm}$ in males); the ratios of ED, IND, IFE, LAL, TYD and LW to SVL of males are significantly higher than that of females, but the ratios of TW to SVL of males is lower than that of females (Table 1). In some adult females, the black transverse bands on limbs are not obvious (Fig. 6C). In some adult females, chest, chin and ventral surface of limbs scattered with continued light-brown spots (Fig. 7A). Some adult females have black cloud stripe with irregular borders on the ventral side (Fig. 7B), but some don't have (Fig. 6D). In some adult females, dorsum uniform brown with little green impression (Fig. 7C) and some adult females have dorsum uniform brown lacking green impression (Fig. 7D).

\section{Skull description}


379

380

381

382

383

384

385

386

387

388

389

390

391

392

393

394

395

396

397

398

399

shorted, ventral ramus outboard and covered the posterior of pterygoid; a pair of pterygoids, outside of the

ventral surface of the squamosal, anterior ramus is the longest, center is inward and leading edge extends to the

orbit, medial ramus shorted and attached to the anterior lateral part of the prootic, posterior ramus edge-on and extend to maxillary; a pair of columellaes situated ventral to the crista parotica (Fig. 8).

\section{Tadpole description}

Body and tail yellowish-brown (Fig. 9A), at Gosner's stage 28-29, TOL 31.6-36.2 mm, SVL 12.1-14.5

$\mathrm{mm}$, other measurements of tadpoles shown in Table S4. Tail 1.5-1.8 times as long as body; TH $25-30 \%$ of

TL in the 28 th stage and $23-28.5 \%$ in the 29 th stage; BW $45.8 \%$ of SVL in the 28 th stage and $46.8 \%$ in the

29th stage; BH $31.4 \%$ of SVL in the 28th stages and $34.9 \%$ in the 29th stage; tail fins lightly colored, tail

muscles with small black spots; tail depth greater than body depth, dorsal fin arising behind the origin of the

tail; maximum depth near mid-length, tip of tail blunt; nostril near snout, eyes positioned dorsally (Fig. 9A);

spiracle on the middle left of body (Fig. 9B); keratodont formula I: 3-3/ III: 1-1 (Fig. 9C); both upper and

lower lips with labial papillae (Fig. 9C); some additional tubercles at the angles of the mouth, usually with

small keratodonts (Fig. 9C).

\section{Sexual dimorphism}

SVL in females approximately 1.8 times that in males (SVL mean $73.6 \mathrm{~mm}$, range $62.4-81.1 \mathrm{~mm}$ in females; SVL mean $41.0 \mathrm{~mm}$, range $36.2-43.3 \mathrm{~mm}$ in males); paired subgular vocal sacs located at corners of throat, pinkish lineae musculinae on dorsal side, nuptial pad light yellow on the inner of first finger from base to subarticular tubercles in males (Figs. 5, 6).

\section{Comparisons}

Odorrana kweichowensis sp. nov. differs from O. amamiensis, O. andersonii, O. bacboensis, $O$. 
400

401

cangyuanensis, O. chapaensis, O. geminata, O. graham, O. hmongorum, O. ishikawae, O. jingdongensis, $O$.

junlianensis, O. kuangwuensis, O. macrotympana, O. margaretae, O. mawphlangensis, O. mutschmanni, and O. wuchuanensis, by having smaller body size $(\mathrm{SVL}<43.30 \mathrm{~mm}$ in males in the new species vs. $\mathrm{SVL}>48$ $\mathrm{mm}$ in males in other species).

Odorrana kweichowensis sp. nov. differs from O. absita, O. aureola, O. banaorum, O. bolavensis, $O$. exiliversabilis, O. gigatympana, O. graminea, O. hosii, O. heatwolei, O. indeprensa, O. khalam, O. leporipes, O. livida, O. monjerai, O. narina, O.nasica, O. nasuta, O. orba, O. supranarina, O. tormota, O. trankieni, O. utsunomiyaorum, O. versabilis, O. yentuensis and $O$. zhaoi, by lacking dorsolateral folds (vs. present in other species).

Odorrana kweichowensis sp. nov. differs from $O$. fengkaiensis by tibiotarsal articulation reaching the level between eye to nostril when leg stretched forward (vs. reaching the level below nostril in the latter); from O. rotodoar by tibiotarsal articulation reaching the level between eye to nostril when leg stretched forward (vs. reaching the level beyond eye in the latter); from O. lipuensis (vocal sacs absence in males) and O. hainanensis (paired internal vocal sacs in males) by paired external vocal sacs located at corners of throat; from $O$. chloronota by having head longer than wide (vs. head wider than long in the latter); from O. morafkai and $O$. sinica by having white pectoral spinules in mature males (vs. absence in the latter); from O. arunachalensis, by the relative finger lengths I $<$ II $<$ IV $<$ III (vs. II $<$ I $<$ IV $<$ III in the latter).

Within the $O$. schmackeri group (O. anlungensis, $O$. hejiangensis, $O$. lungshengensis, $O$. nanjiangensis, $O$. swinhoana, O. tianmuii, O. tiannanensis, O. yizhangensis, O. huanggangensis and O. schmackeri), Odorrana kweichowensis sp. nov. differs from $O$. anlungensis by having white pectoral spinules in mature males (vs. absence in the latter), tibiotarsal articulation reaching the level between eye to nostril when leg stretched 
421

forward (vs. reaching the nostril in the latter), web becoming narrower and continuing to the disks of toe IV

(vs. web continuing to the subarticular tubercles of toe IV in the latter); from $O$. hejiangensis by the disks of fingers with circum-marginal grooves (vs. without circum-marginal grooves on finger I in the latter), two metacarpal tubercles (vs. three metacarpal tubercles in the latter); from O. lungshengensis by the body size of males with maximum SVL $43.3 \mathrm{~mm}$ (vs. SVL $50.0-59.6 \mathrm{~mm}$ of males in the latter), tympanum large and distinct, and beyond twice as long as width of distal phalanx of finger III (vs. tympanum as long as width of distal phalanx of finger III in the latter), two metacarpal tubercles (vs. without outer metacarpal tubercle in the latter), tibiotarsal articulation reaching the level between eye to nostril when leg stretched forward (vs. reaching the tip of snout in the latter); from O. nanjiangensis by the body size in males with maximum SVL $43.3 \mathrm{~mm}$ (vs. SVL 59.5-66.8 $\mathrm{mm}$ in males in the latter), two metacarpal tubercles (vs. without outer metacarpal tubercle in the latter), tibiotarsal articulation reaching the level between eye to nostril when leg stretched forward (vs. reaching the tip of snout in the latter); from O. swinhoana by the body size in males with maximum SVL $43.3 \mathrm{~mm}$ (vs. SVL 47.7-71.6 $\mathrm{mm}$ in males in the latter), tibiotarsal articulation reaching the level between eye to nostril when leg stretched forward (vs. reaching the tip of snout); from O. tianmuii by the relative finger lengths II $<$ I $<$ IV $<$ III (vs. I $<$ II $<$ IV $<$ III in the latter), two metacarpal tubercles (vs. three outer metacarpal tubercles in the latter); O. tiannanensis by the body size in males with maximum SVL 43.3 $\mathrm{mm}$ (vs. SVL 52.5-53.5 $\mathrm{mm}$ in males in the latter), tibiotarsal articulation reaching the level between eye to nostril when leg stretched forward (vs. reaching the level beyond the tip of snout in the latter); O. yizhangensis by the body size in males with maximum SVL $43.3 \mathrm{~mm}$ (vs. SVL $47.3-54.0 \mathrm{~mm}$ in males in the latter), two metacarpal tubercles (vs. without outer metacarpal tubercle), tibiotarsal articulation reaching the level between eye to nostril when leg stretched forward (vs. reaching the tip of snout in the latter); from O. huanggangensis 
442 by the relative finger lengths II $<$ I $<$ IV $<$ III (vs. I $<$ II $<$ IV $<$ III in the latter), tibiotarsal articulation reaching

443 the level between eye to nostril when leg stretched forward (vs. reaching the nostril in the latter); from $O$.

444 schmackeri, by the first subarticular tubercle on fingers and supernumerary tubercles being weak (vs. being

445 outstanding in the latter; Fig. 5E, F), and having two outer metacarpal tubercles (vs. outer metacarpal tubercle

446 being indistinct in the latter; Fig. 5H, G).

Odorrana kweichowensis sp. nov. differs from $O$. schmackeri by having significantly lower ratios of HDL

448

and SL to SVL in males, having significantly higher ratios of THL, TL and FL to SVL in males, and having

significantly higher ratios of IND, THL, TL and FL to SVL in females (all $p$-values $<0.05$; Table 1; Table S6);

from $O$. huanggangensis by having significantly lower ratios of NSL and IAE to SVL in males, having

significantly higher ratios of IND, LAL, THL and TFL to SVL in males, and having significantly higher ratios

of LAL, THL, TL and FL to SVL in females (all $p$-values $<0.05$; Table 1; Table S6).

\section{Ecology}

To present, Odorrana kweichowensis sp. nov. has been found in three localities: Lengshuihe Nature

Reserve $\left(27^{\circ} 34^{\prime}-27^{\circ} 26^{\prime} \mathrm{N}, 1^{\circ} 5^{\circ} 57^{\prime}-106^{\circ} 04^{\prime}\right.$ E) in Jinsha Co., Meitan Co. $\left(27^{\circ} 39^{\prime}-27^{\circ} 42^{\prime}\right.$ N, $1^{0} 7^{\circ} 33^{\prime}-107^{\circ} 35^{\prime}$ E)

and Zheng'an Co. $\left(28^{\circ} 09^{\prime}-28^{\circ} 20^{\prime}\right.$ N, 107 $30^{\prime}-107^{\circ} 38^{\prime}$ E) in Guizhou Prov. of China. Geographical distances

between these localities were from $89 \mathrm{~km}$ to $173 \mathrm{~km}$. Population from the Lengshuihe Nature Reserve

inhabited broad streams, and near the riparian areas, surrounded by evergreen broadleaved forests (Fig. 10A).

Populations from Meitan Co. and Zheng'an Co. inhabited broad slow-flowing rivers surrounded by paddy field

(Fig. 10B and C). All of the localities were at elevations 717-766 m. All adult individuals that we found appear on the stones in the streams at night $(07: 30-12: 00 \mathrm{pm})$ with water $\mathrm{pH} 6.8-7.1$ and water temperature $15-23{ }^{\circ} \mathrm{C}$.

Tadpoles could be found at daytime and night. Amplexed individuals could be found in the streams in the type 
locality (Fig. 10A). Three sympatric amphibian species Fejervarya multistriata, Rana zhenhaiensis and

464

465

466

467

468

469

470

471

472

473

474

475

476

477

478

479

480

481

482

483

Polypedates megacephalus were found in Meitan Co. and Zheng'an Co., but only one sympatric amphibian species Amolops chunganensis was found in the Lengshuihe Nature Reserve in the type locality.

\section{Etymology}

The specific epithet "kweichowensis" refers to the distribution of this species, Guizhou Prov., China. The "kweichow" is an old spelling and a transliteration for "Guizhou". We propose the common English name “Guizhou Odorous Frog” for this species.

\section{DISCUSSION}

Morphological similarity of related species in the genus Odorrana challenges classifications in the group (Fei et al., 2009; Chen et al., 2013). Integrative taxonomy with multiple evidences, such as genetic divergence, ecological discrepancy, morphometric differences, and so on, turns out to be quite effective, and have already become the main trend. In this study, based on molecular phylogenetic analyses and morphological comparisons, a new species, Odorrana kweichowensis sp. nov., was described from mountain streams in Guizhou Prov., China. Phylogenetic analyses based on mitochondrial DNA suggested that the new species belonged to Odorrana but was significantly separated from its congeners. Genetic distance based on $16 \mathrm{~S}$ rRNA gene between it and its sister species $O$. schmackeri was mean 0.027 , matching the level about interspecific divergences in amphibians (0.01-0.17; Vences et al. 2005) and being much higher than that between many sister species (of which, most species have been completely recognized as valid species) in Odorrana. Moreover, on nuclear protein-coding genes which presented much lower evolutionary rates, the new species was still indicated to occupy an independent lineage separated from other species. These results 
484

confirmed restricted even absent gene flow between the new species and its related species. Finally, the new species was different from its congeners on a lot of morphological characters. At all, multiple evidences supported the validity of the new species.

In this study, Odorrana kweichowensis sp. nov. was found in three localities in the northwestern part of Guizhou Prov. of China (Fig. 1). In Li et al. (2015), the new species was only found in two localities in Guizhou Prov.: one was the type locality (Lengshuihe Reserve in Jinsha Co.) of it, and another was the Suiyang Co. closely adjoining Meitan Co. and Zheng'an Co. included in this study. Obviously, it could be speculated that the new species was at least distributed in the northwestern part of Guizhou Prov. of China (Fig. 1). Unfortunately, it was still not sure whether the new species was conspecific with Odorrana sp1 recognized by Zhu et al. (2016) in absence of corresponding specimens and sequences. If they were conspecific, the new species should be distributed in a larger range from northern Guizhou Prov. to southern Guangxi Prov., China. In addition, it could not infer whether the populations in northern Thailand and northern Vietnam reported as $O$. schmackeri (Chan-ard, 2003; Orlov et al., 2002; Nguyen et al., 2005; Fig. 1) was conspecific with the new species, because there was also no molecular data and detailed morphological descriptions of them. As note, according to previous studies (Li et al., 2015; Zhu, 2016) and our results, the new species was possibly sympatric with Clade D (Odorrana sp2) recognized by Zhu (2016) and O. hejiangensis in a narrow area along the boundary between northern Guizhou Prov. and Sichuan Prov. and Chongqing City, China (Fig. 1), though in the localities investigated in this study, we did not find the latter two species in the microhabitats of the new species. 
Guizhou Prov. of China, and provide evidence for its phylogenetic allocations. Odorrana kweichowensis sp.

nov. was only known from a narrow range in the northwestern part of Guizhou Prov. of China, and occurred

species was found to be seriously threatened by local villager and construction of dams and roads. Thus,

further more detailed investigations on the species are urgent to ascertain its distributional range and

population status. With our description we contributed to a better knowledge of the diversity of the genus

Odorrana in the southwestern China, and thus suggested that more comprehensive phylogeographic studies would highlight radiation patterns of the group.

\section{ACKNOWLEDGEMENTS}

We thank C. Li and C.L. Liao on helping collection of samples. We are much indebted to the editor and referees for their valuable comments.

\section{REFERENCES}

Ahl E. 1927 "1925". Über vernachlässigte Merkmale bei Fröschen. Sitzungsberichte der Gesellschaft Naturforschender Freunde zu Berlin 1925: 40-47

Bain RH, Lathrop A, Murphy RW, Orlov NL, Cuc HT. 2003. Cryptic species of a cascade frog from Southeast Asia: taxonomic revisions and descriptions of six new species. American Museum Novitates

Bain RH, Stuart BL, Nguyen TQ, Che J, Rao DQ. 2009. A New Odorrana (Amphibia: Ranidae) from 
Vietnam and China. Copeia 2: 348-362

Bain RH, Stuart BL. 2005. A new species of cascade frog (Amphibia: Ranidae) from Thailand, with new data on Rana banaorum and Rana morafkai. Natural History Bulletin of the Siam Society 53(1): 3-16

Blyth E. 1856 "1855". Report for October Meeting, 1855. Journal of the Asiatic Society of Bengal 24: 711723

Boettger O. 1892. Katalog der Batrachier-Sammlung im Museum der Senckenbergischen Naturforsch Gesellsch, Frankfurt am Main, 1-73

Boulenger GA. 1882. Calalogue of the Batrachia Salientias. Ecaudata in the Collection of the British Museum. London

Boulenger GA. 1891. On new or little-known Indian and Malayan reptiles and batrachians. Annals and Magazine of Natural History, Series 6, 8: 288-292

Boulenger GA. 1900 "1899". On the reptiles, batrachians, and fishes collected by the late Mr. John Whitehead in the interior of Hainan. Proceedings of the Zoological Society of London 1899: 956-962

Boulenger GA. 1903. Descriptions of new batrachians in the British Museum. Annals and Magazine of Natural History, London, 12(7): 552-557

Boulenger GA. 1917. Descriptions of new frogs of the genus Rana. Annals and Magazine of Natural History, London, 20(8): 413-418

Bourret R. 1937. Notes herpétologiques sur l'Indochinese francaise. XIV. Les batrachiens de la collection du Laboratoire des Sciences naturelles de l'Université. Descriptions de quinze espèces ou variétés nouvelles. Annexe au Bulletin Général de l'Instruction Publique, 4: 5-56 
547

548

549

550

551

552

553

554

555

556

557

558

559

560

561

562

563

564

565

566

567

phylogenetic position of the rare Chinese frog, Amolops tormotus. Zootaxa 1531: 49-55

Castresana J. 2000. Selection of conserved blocks from multiple alignments for their use in phylogenetic analysis.Molecular Biology and Evolution 17: 540-552

Chan-ard T. 2003. A Photographic Guide to Amphibians in Thailand [In Thai]. Bangkok, Thailand: Darnsutha Press Co., Ltd.

Che J, Pang JF, Zhao H, Wu GF, Zhao E M, Zhang YP. 2007. Phylogeny of Raninae (Anura: Ranidae) inferred from mitochondrial and nuclear sequences. Molecular Phylogenetics and Evolution 43: 1-13

Chen XH, Chen Z, Jiang JP, Qiao L, Lu YQ, Zhou KY, Zheng GG, Zhai XF, Liu JX. 2013. Molecular phylogeny and diversification of the genus Odorrana (Amphibia, Anura, Ranidae) inferred from two mitochondrial genes. Molecular Phylogenetics and Evolution 69: 1196-1202

Chen XH, Zhou KY, Zheng GM. 2010a. A new species of odor frog from China (Anura: Ranidae). Journal of Beijing Normal University (Natural Science) 46(5): 606-609

Chen XH, Zhou KY, Zheng GM. 2010b. A new species of the genus Odorrana from China (Anura, Ranidae). Acta Zootaxonomica Sinica 35(1): 206-211

Clement M, Posada D, Crandall K. 2000. TCS: a computer program to estimate gene genealogies. Molecular Ecology 9: 1657-1660

Deng QX, Yu ZW. 1992. A new species of the genus Rana form China. Journal of Sichuan Teacher College 13(4): $323-326$

Fei L, Hu SQ, Ye CY, Huang YZ. 2009. Fauna Sinica, Amphibia Vol. 3, Anura Ranidae. Beijing: Science Press

Fei L, Ye CY, Huang YZ. 1990. Key to Chinese Amphibians. Chongqing Branch Sci. Technol. Literature 
Press, Chongqing

Fei L, Ye CY, Jiang JP. 2007b. A new Ranidae frog species China Odorrana (Odorrana) yizhangensis (Ranidae: Anura). Acat Zoological Sinica 32(4): 989-992

Fei L, Ye CY, Jiang JP. 2012. Colored atlas of Chinese Amphibians and their distributions. Chengdu: Sichuan Publishing House of Science and Technology

Fei L, Ye CY, Li C. 2001a. Descriptions of two new species of the genus Odorrana in China (Anura: Ranidae). Acta Zootaxonomica Sinica 26(1): 108-114

Fei L, Ye CY, Li C. 2001b. Taxonomic studies of Odorrana versabilis in China II. Descriptions of two new species (Amphibian: Ranidae). Acta Zootaxonomica Sinica 26(4): 601-607

Fei L, Ye CY, Xie F. 2007a. A new Ranidae frog species from Sichuan, China Odorrana (Odorrana) nanjiangensis (Ranidae: Anura). Zoological Research 28: 551-555

Fei L, Ye CY. 2001. The color handbook of the amphibians of Sichuan. Beijing: Chinese Forestry Press

Frost DR. 2018. Amphibian Species of the World Version 6.0. American Museum of Natural History, New York, USA. Available from: http://research.amnh.org/vz/herpetology/amphibia/ (accessed 11 March 2018)

Gosner K L.1960. A Simplified Table for Staging Anuran Embryos and Larvae with Notes on Identification. Herpetologica 16(3): 183-190

Guindon S, Dufayard JF, Lefort V, Anisimova M, Hordijk W, Gascuel O. 2010. New algorithms and methods to estimate maximum-likelihood phylogenies: assessing the performance of PhyML 3.0. Systematic Biology 59(3): 307-321

Günther ACLG. 1876 "1875". Third report on collections of Indian reptiles obtained by the British Museum. Proceedings of the Zoological Society of London 1875: 567-577 
Hall TA. 1999. BIOEDIT: a user-friendly biological sequence alignment editor and analysis program for Windows 95/98/NT. In Nucleic acids symposium series 41: 95-98

He YX. 2017. Molecular phylogeny of the genus Odorrana inferred from mitochondrial and multiple nuclear genes. Henan Normal University

Hu SX, Zhao EM, Liu CZ. 1966. A herpetological survey of the Tsinling and Ta-pa shan region. Acat Zoological Sinica 18(1): 57-89

Hu SX, Zhao EM, Liu CZ. 1973. A survey of amphibians and reptiles in Kweichow province, including a herpetofauna analysis. Acat Zoological Sinica 19(2): 149-171

Huson DH, Bryant D. 2006. Application of phylogenetic networks in evolutionary studies. Molecular Biology and Eevolution 23: 254-267

Kocher TDWK, Thomas A. 1989. Dynamics of mitochondrial DNA evolution in mammals: Amplification and sequencing with conserved Primers. Proceedings of the National Academy of Sciences of the United States of America 86: 6169-6200

Kuramoto M, Satou N, Oumi S, Kurabayashi A, Sumida M. 2011. Inter- and intra-island divergence in Odorrana ishikawae (Anura, Ranidae) of the Ryukyu Archipelago of Japan, with description of a new species. Zootaxa 2767: 25-40

Lanfear R, Calcott B., Ho SY, Guindon S. 2012. Partitionfinder: combined selection of partitioning schemes and substitution models for phylogenetic analyses. Molecular Biology and Evolution 29: 1695-1701

Lemmon AR, Moriarty EC. 2004. The importance of proper model assumption in Bayesian phylogenetics. Systematic Biology 53: 265-277

Li PP, Lu YY, Rao DQ. 2008. A new species of cascade frog (Amphibia, Ranidae) from Tibet, China. Acta 
611 Li YM, Wu XY, Zhang HB, Yan P, Xue H, Wu XB. 2015. Vicariance and its impact on the molecular ecology of a Chinese Ranid frog species-complex (Odorrana schmackeri, Ranidae). PLOS ONE 10(9): e0138757

Liu CC, Hu SQ.1961. Chinese Amphibians (Anura). Beijing: Science Press

Liu CZ, Hu SQ. 1962. A survey of amphibians and reptiles in Guangxi province, Acat Zoological Sinica 14: $73-104$

Liu CZ. 1950. Amphibian of western China. Fieldiana: Zoology Museum, Chicago 2: 1-400

Matsui M, Jaafar I. 2006. A new cascade frog of the subgenus Odorrana from peninsular Malaysia. Zoological Science 23(7): 647-651 darkness in a karst cave in Guangxi, China. Asian Herpetological Research 6(1): 11-17

Matsui M, Shimada T, Ota H, Tanaka-Ueno T. 2005. Multiple invasions of the Ryukyu Archipelago by Oriental frogs of the subgenus Odorrana with phylogenetic reassessment of the related subgenera of the genus Rana. Molecular Phylogenetics and Evolution 37: 733-742

Matsui M. 1994. A taxonomic study of the Rana narina complex, with description of three new species (Amphibia: Ranidae). Zoological Journal of the Linnean Society 111: 385-415

McGuire JA, Witt CC, Altshule DL, Remsen JV. 2007. Phylogenetic systematics and biogeography of hummingbirds: Bayesian and maximum likelihood analyses of partitioned data and selection of an appropriate partitioning strategy. Systematic Biology 56: 837-856

Mo YM, Chen WC, Wu HY, Zhang W, Zhou SC. 2015. A new species of Odorrana inhabiting complete

Ngo A, Murphy RW, Liu WZ, Orlov NL. 2006. The phylogenetic relationships of the Chinese and 
Vietnamese waterfall frogs of the genus Amolops. Amphibia Reptilia 27(1): 81- 92

632

633

634

635

636

640

641

642

643

644

645

646

647

648

649

650

651

Nguyen SV, Ho CT, Nguyen TQ. 2005. Danh Luc Ech Nhai Va Bo Sat Viet Nam/A Checklist of the

Amphibians and Reptiles of Vietnam. Hanoi: Nha Xuat Ban Hong Nghiep

Orlov NL, Natalia BA, Cuc HT. 2006. A new cascade frog (Amphibia: Ranidae) from central Vietnam. Russian Journal of Herpetology 13(2): 155-163

Orlov NL, Ngat LN, Cuc HT. 2003. A new species of cascade frog from north Vietnam (Ranidae, Anura). Russian Journal of Herpetology 10(2): 123-134

Orlov, NL, Murphy RW, Ananjeva NB, Ryabov SA, Ho CT. 2002. Herpetofauna of Vietnam, a checklist. Part 1. Amphibia. Russian Journal of Herpetology 9: 81-104

Pham CT, Nguyen TQ, Le MD, Bonkowski M, Ziegler T. 2016. A new species of Odorrana (Amphibia: Anura: Ranidae) from Vietnam. Zootaxa 4084: 421-435

Pillai RS, Chanda SK. 1977. Two new species of frogs (Ranidae) from Khasi Hills, India. Journal of the Bombay Natural History Society 74: 136-140

Pyron RA, Wiens JJ. 2011. A large-scale phylogeny of amphibia including over 2800 species, and a revised classification of extant frogs, salamanders, and caecilians. Molecular Phylogenetics and Evolution 61: $543-583$

R Development Core Team. 2008. R: a language and environment for statistical computing. R Foundation for Statistical Computing. Vienna: Available at http://www.R-project.org.

Ronquist FR, Huelsenbeck JP. 2003. MrBayes3: Bayesian phylogenetic inference under mixed models. Bioinformatics 19(12): 1572-1574

Saikia B, Sinha B, Kharkongor IJ. 2017. Odorrana arunachalensis: A new species of Cascade Frog (Anura: 
652

653

654

655

656

657

658

659

660

661

662

663

664

665

666

667

668

669

670

671

672

Ranidae) from Talle Valley Wildlife Sanctuary, Arunachal Pradesh, India. Journal of Bioresources.

Arunachal Pradesh, India 4: 30-41

Sambrook J, Fritsch EF, Maniatis T. 1989. Molecular Cloning: A Laboratory Manual. New York: Cold Spring Harbor Laboratory Press

Shen XX, Liang D, Feng YJ, Chen MY, Zhang P. 2013. A versatile and highly efficient toolkit including 102 nuclear markers for vertebrate phylogenomics, tested by resolving the higher level relationships of the Caudata. Molecular Biology and Eevolution 30(10): 2235-2248

Simon C, Frari F, Beckenbach A, Crespi B, Liu H, Flook P. 1994. Evolution, weighting and Phylogenetic utility of mitochondrial gene sequences and a compilation of conserved Polymerase chain reaction Primers. Annals of the Entomological Society of America 87(6): 651-701

Stejneger L. 1901. Diagnoses of eight new batrachians and reptiles from the Riu Kiu Archipelago, Japan. Proceedings of the Biological Society of Washington 14: 189-191

Stuart BL, Bain RH. 2005. Three new species of spinule-bearing frogs allied to Rana megatympanum Bain, Lathrop, Murphy, Orlov and Ho, 2003 from Laos and Vietnam. Herpetologica 61: 478-492

Stuart BL, Chan-ard T. 2005. Two new Huia (Amphibia: Ranidae) from Laos and Thailand. Copeia 2: 279289

Stuart BL, Chuaynkern Y, Chan-ard T, Inger RF. 2006. Three new species of frogs and a new tadpole from eastern Thailand. Fieldiana Zoology, new series 111: 1-19

Stuart BL, Orlov NL, Chan-ard T. 2005. A new cascade frog (Amphibia: Ranidae) from Laos and Vietnam.The Raffles Bull Zool 53: 125-131

Stuart BL. 2008. The phylogenetic problem of Huia (Amphibia: Ranidae). Molecular Phylogenetics and 
Evolution 46: 49-60

Tamura K, Stecher G, Peterson D, Fiipski A, Kumar S. 2011. MEGA6: molecular evolutionary genetics analysis using evolutionary distance. Molecular Biology and Evolution 28: 2725-2729

Tran TT, Orlov NL, Nguyen TT. 2008. A new species of Cascade Frog of Odorrana Fei, Yi et Huang, 1990 genus (Amphibia: Anura: Ranidae) from Bac Giang Province (Yen Tu Mountain Range, northeast Vietnam). Russian Journal of Herpetology 15: 212-224

Vences M, Thomas M, Meijden A, Chiari Y, Vieites DR. 2005. Comparative performance of the 16S rRNA gene in DNA barcoding of amphibians. Frontiers in Zoology 2: 5

Wang YY, Lau N, Yang JH, Chen GL, Liu ZY, Pang H, Liu Y. 2015. A new species of the genus Odorrana (Amphibia: Ranidae) and the first record of Odorrana bacboensis from China. Zootaxa 3999(2): 235-254

Werner F. 1930. Rana leporipes, a new species of frog from South China, with field notes by R. Mell. Lingnan Science Journal. Canton 9: 45-47

Wiens JJ, Sukumaran J, Pyron RA, Brown RM. 2009. Evolutionary and biogeographic origins of high tropical diversity in old world frogs (Ranidae). Evolution 63(5): 1217-1231

Wu GF. 1977. A new species of frogs from Huang-Shan, Anhui, Amolops tormotus Wu. Acta Zoologica Sinica 23: 113-115

Wu L, Xu RH, Dong Q, Li DJ, Liu JS. 1983. A new species of Rana and records of amphibians from Guizhou province. Acta Zootaxonomica Sinica 29(1): 66-70

Yang DT, Li SM. 1980. A New Species of the Genus Rana from Yunnan. Zoological Research 1 (2): 261-264

Yang DT. 2008. Amphibia and Reptilia of Yunnan. Kunming: Yunnan Publishing Group Corporation, 
$694 \quad$ Yunnan Science and Technology Press

695 Ye CY, Fei L. 2001. Phylogeny of genus Odorrana (Amphibian: Randiae) in China. Acta Zoologica Sinica $696 \quad$ 47(5): $528-534$

697 Zhu YJ. 2016. Genetic differentiation of odorrana schmackeri species complex. Henan Normal University 


\section{Table $\mathbf{1}$ (on next page)}

The results of one-way ANOVA with $p$-values for morphometric comparisons between Odorrana kweichowensis sp. nov., O. schmackeri and $O$. huanggangensis.

$\mathrm{OK}, \mathrm{O}$. kweichowensis sp. nov.; OS, O. schmackeri; $\mathrm{OH}, \mathrm{O}$. huanggangensis. Significance level: $* p<0.05$; $* *<0.01 ; * * *<0.001$. Abbreviations for the morphometric characters refer to Methods section. 


\begin{tabular}{clllll}
\hline \multirow{2}{*}{ Males of $O K$ vs. Females of $O K$} & \multicolumn{2}{c}{ In males } & \multicolumn{2}{c}{ In females } \\
\cline { 3 - 6 } SVL & $0.0001^{* * *}$ & $O K$ vs. $O S$ & $O K$ vs. $O H$ & $O K$ vs. $O S$ & $O K$ vs. $O H$ \\
\hline HDL & 0.5560 & 0.3160 & 0.2370 & 0.0810 & 0.4520 \\
\hline HDW & 0.6240 & $0.0030^{* *}$ & 0.5740 & 0.0900 & 0.0540 \\
SL & 0.9840 & 0.2100 & 0.7650 & 0.0560 & 0.9000 \\
\hline ED & $0.0001^{* * *}$ & $0.0130^{*}$ & 0.1130 & 0.0740 & 0.9860 \\
\hline IOD & 0.1470 & 0.4730 & 0.2510 & 0.1560 & 0.9130 \\
\hline IND & $0.0210^{*}$ & 0.0910 & 0.2370 & 0.4520 & 0.2880 \\
NED & 0.1470 & 0.5770 & $0.0330^{*}$ & $0.0290^{*}$ & 0.8340 \\
\hline NSD & 0.8830 & 0.2790 & 0.8480 & 0.4940 & 0.8860 \\
\hline IFE & $0.0001^{* * *}$ & 0.0980 & $0.0430^{*}$ & 0.3060 & $0.0310^{*}$ \\
\hline IAE & $0.0001^{* * *}$ & 0.2140 & 0.3870 & 0.0740 & 0.6930 \\
\hline TYD & $0.0001^{* * *}$ & $0.0490^{*}$ & $0.0310^{*}$ & 0.2320 & 0.2060 \\
\hline LAL & 0.3340 & 0.1960 & 0.2980 & 0.9260 & 0.1040 \\
\hline LW & $0.0040^{* *}$ & 0.0950 & $0.0310^{*}$ & $0.0320^{*}$ & $0.0000^{* * *}$ \\
\hline THL & 0.7560 & 0.1090 & 0.1390 & 0.3510 & 0.6420 \\
\hline TL & 0.0920 & $0.0110^{*}$ & $0.0240^{*}$ & $0.0270 *$ & $0.0000^{*}$ \\
\hline TW & $0.0220^{*}$ & $0.0170^{*}$ & 0.1970 & $0.0420^{*}$ & $0.0040^{* *}$ \\
TFL & 0.9930 & 0.0840 & 0.1430 & 0.1500 & $0.0160^{*}$ \\
\hline FL & 0.2690 & 0.0540 & $0.0290^{*}$ & 0.0500 & 0.0390 \\
\hline FDW & 0.3400 & $0.0170^{*}$ & 0.2410 & 0.0270 & $0.0050^{* *}$ \\
\hline DPW & 0.5490 & 0.0840 & 0.5660 & 0.9480 & 0.5520 \\
\hline & & 0.1040 & 0.6290 & 0.4520 & 0.6510 \\
\hline
\end{tabular}




\section{Figure 1}

Sampling localities in this study.

Localities 1-8 were all in China. 1, Jinsha County (Co.), Guizhou Province (Prov.); 2, Zheng'an Co., Guizhou Prov.; 3, Meitan Co., Guizhou Prov.; 4, Leishan Co., Guizhou Prov.; 5, Jiangkou Co., Guizhou Prov.; 6, Sangzhi Co., Hunan Prov.; 7, Changyang Co., Hubei Prov.; 8, Ruyuan Co., Guangdong Prov.. According to literatures and results in this study, the distributional range of each related species was surrounded by dotted lines on the map. Odorrana sp1 and Odorrana sp2 were proposed in Zhu (2016); Odorrana sp3 was corresponding to the third cryptic species (Clade F) proposed in Li et al. (2015). Different species were denoted as different colors and shapes. 


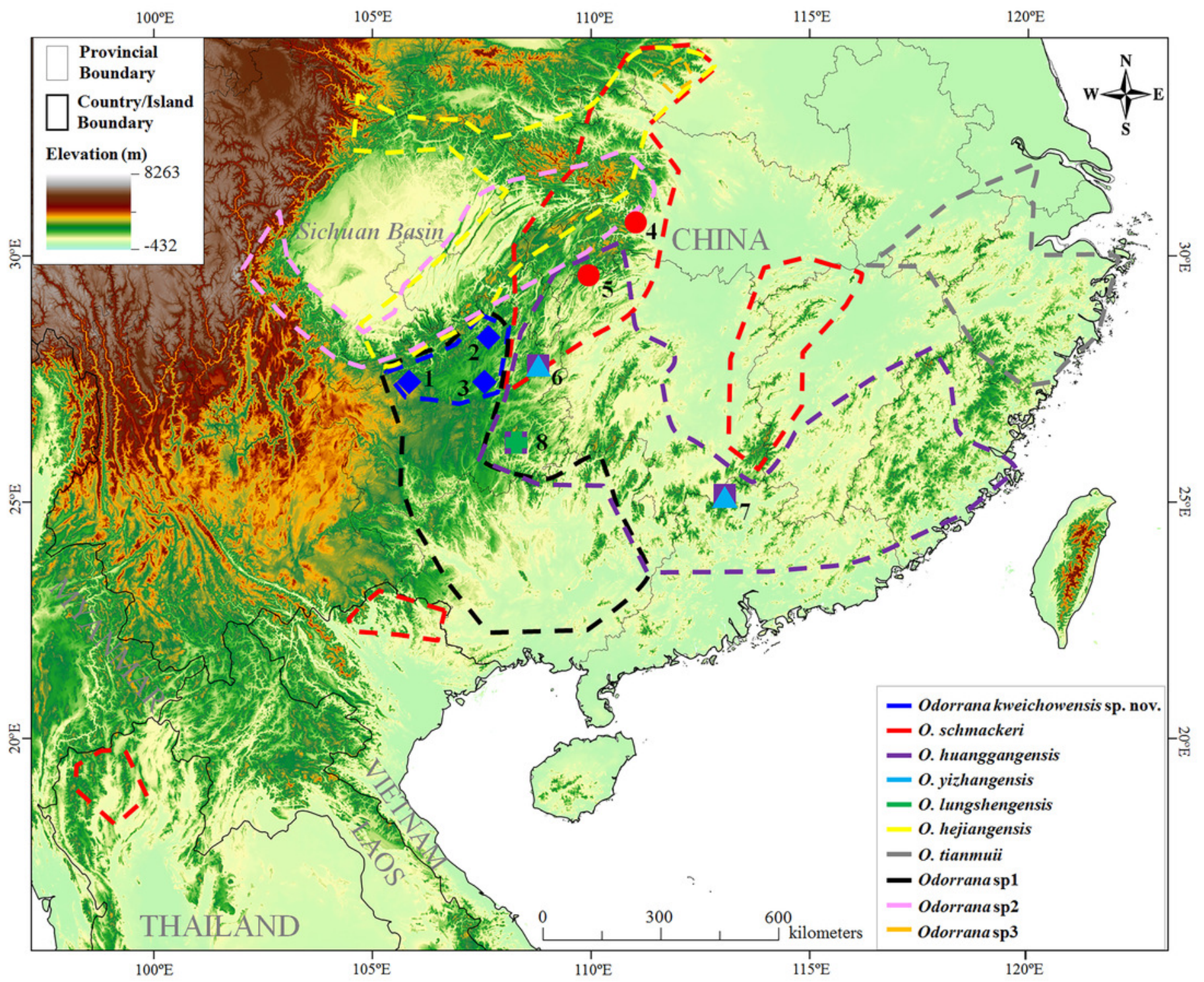


Figure 2

Phylogenetic relationships of Odorrana kweichowensis sp. nov. and its congeners.

(A) Maximum likelihood (ML) tree reconstructed based on the three genes (12S $+16 \mathrm{~S}+$ ND2) concatenated dataset. (B) Phylogenetic network of $O$. kweichowensis sp. nov. and its related species reconstructed by the software Splittree based on ND2 gene sequences. In ML tree, bootstrap supports (BS) from ML analyses/Bayesian posterior probabilities (BPP) from BI analyses were noted beside nodes. In Splittree network, numbers on branches are BS. Odorrana sp2 was proposed in Zhu (2016); Odorrana sp3 was corresponding to the third cryptic species (Clade F) in Li et al. (2015). Different related species of Odorrana kweichowensis sp. nov. were denoted as different colors.
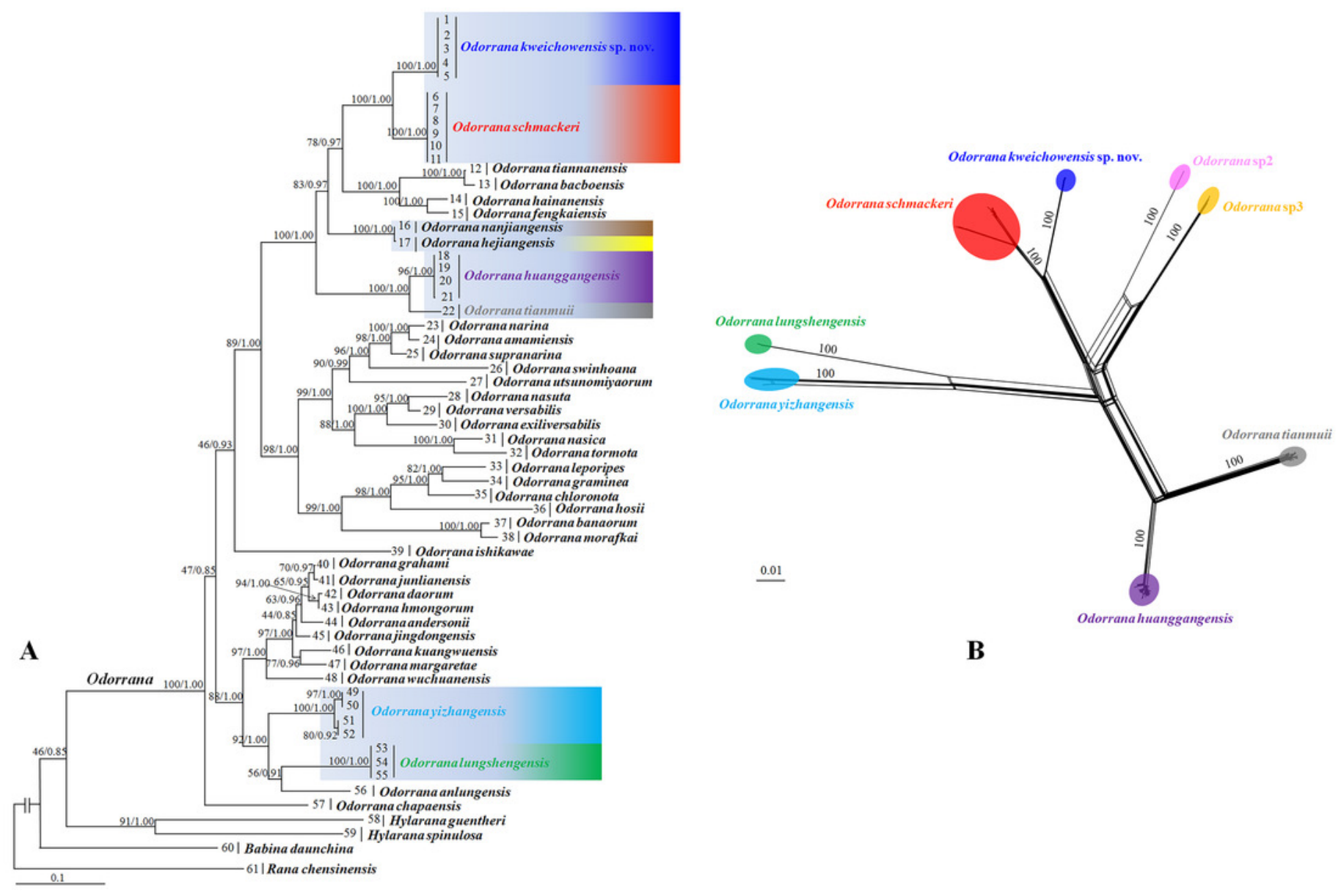
Figure 3

Haplotype networks of $O$. kweichowensis sp. nov. and its related species constructed based on the nuclear gene sequences.

(A) DOLK gene. (B) KCNF gene. Different species were denoted as different colors.

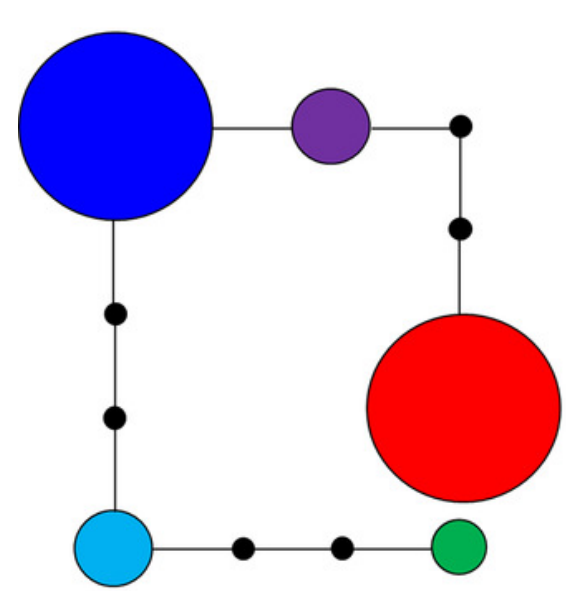

A

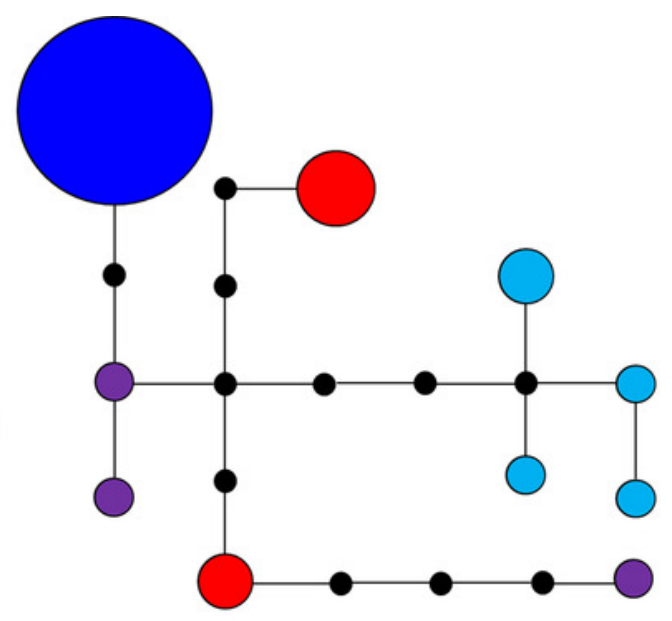

B
Odorrana kweichowensis sp. nov.

o. schmackeri

O. huanggangensis

o. yizhangensis

O. lungshengensis

Number of samples

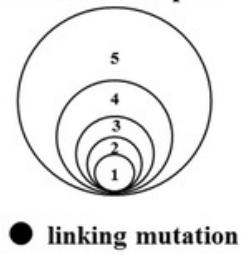




\section{Figure 4}

Plots of principal component analyses of Odorrana kweichowensis sp. nov., 0 . schmackeri and 0 . huanggangnesis.

(A) Males. (B) Females. $\mathrm{PC} 1$, the first principal component; $\mathrm{PC2}$, the second principal component. Different species were denoted as different colors and shapes.
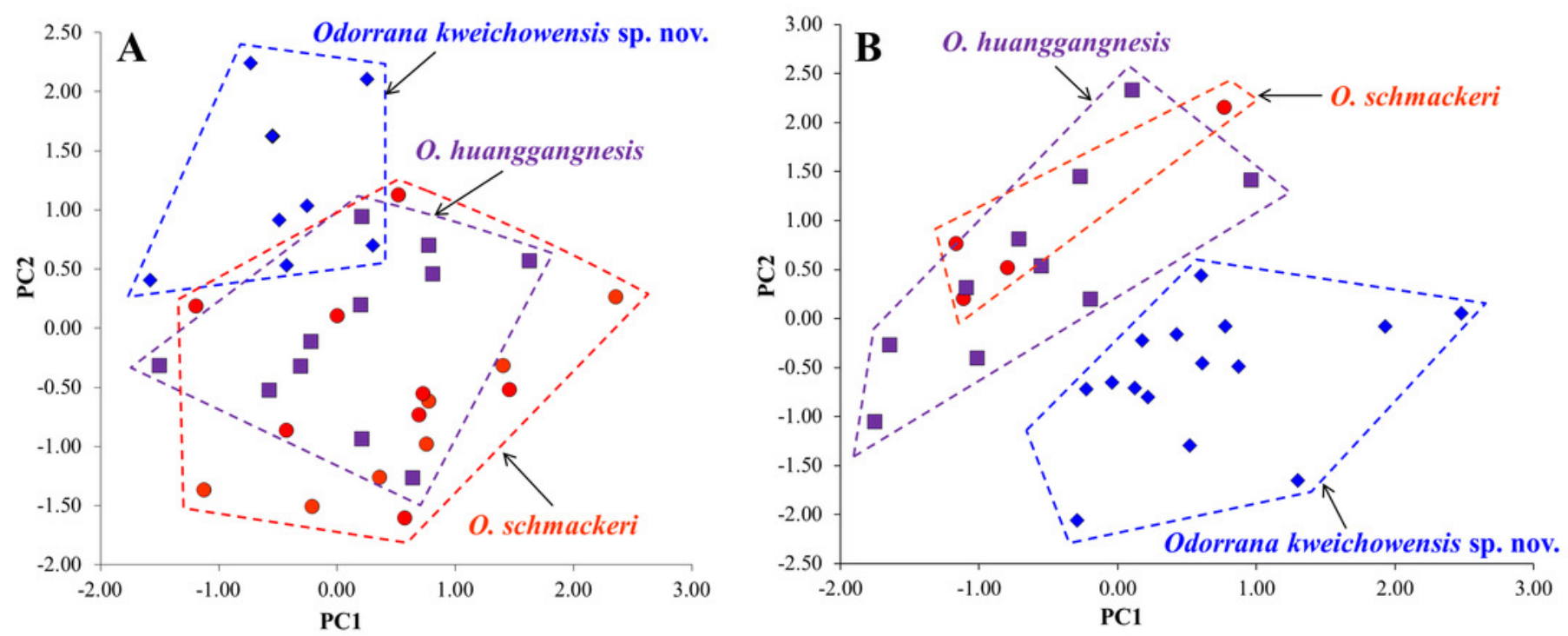


\section{Figure 5}

Comparisons of the holotype (voucher number: CIBjs20150803002) of Odorrana kweichowensis sp. nov. and one male specimen (voucher number: CIBsz2012062003) of O. schmackeri.

(A) and (B), dorsal view and ventral view of specimen CIBjs20150803002, respectively. (C) and (D), dorsal view and ventral view of specimen CIBsz2012062003, respectively. (E) Ventral view of hand of specimens CIBjs20150803002. (F) Ventral view of hand of specimen CIBsz2012062003. (G) Ventral view of foot of specimen CIBjs20150803002. (H) Ventral view of foot of specimen ClBsz2012062003. Photographs by S.Z. Li.

*Note: Auto Gamma Correction was used for the image. This only affects the reviewing manuscript. See original source image if needed for review. 


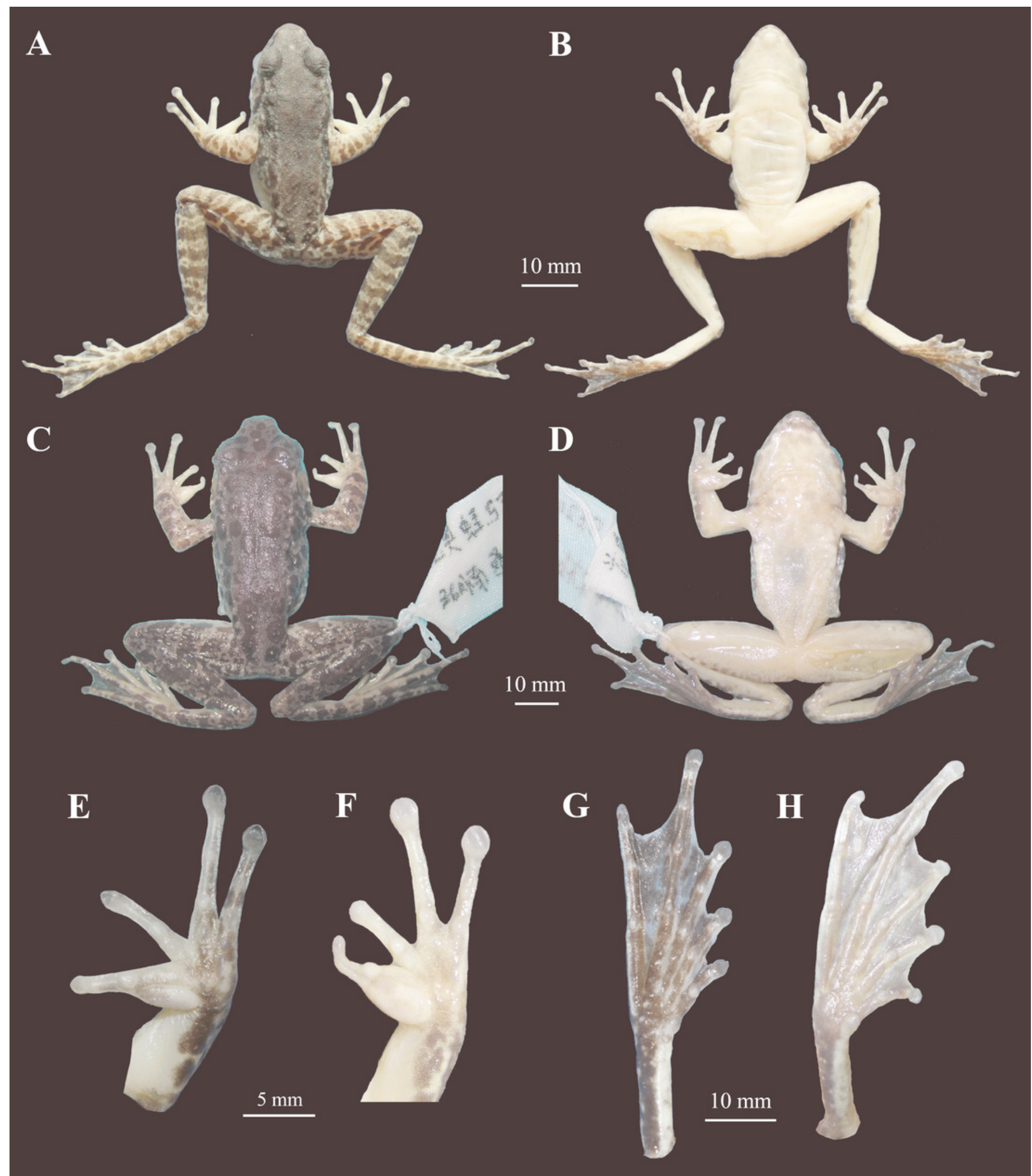




\section{Figure 6}

Living Odorrana kweichowensis sp. nov. from its type locality, Lengshihe Nature Reserve in Jinsha County, Guizhou Province, China.

(A) and (B), dorsolateral view and ventral view of an adult male (voucher number: CIBjs20150803002), respectively. (C) and (D), dorsolateral view and ventral view of an adult female (voucher number: CIBjs20150803006), respectively. Photographs by S.Z. Li.

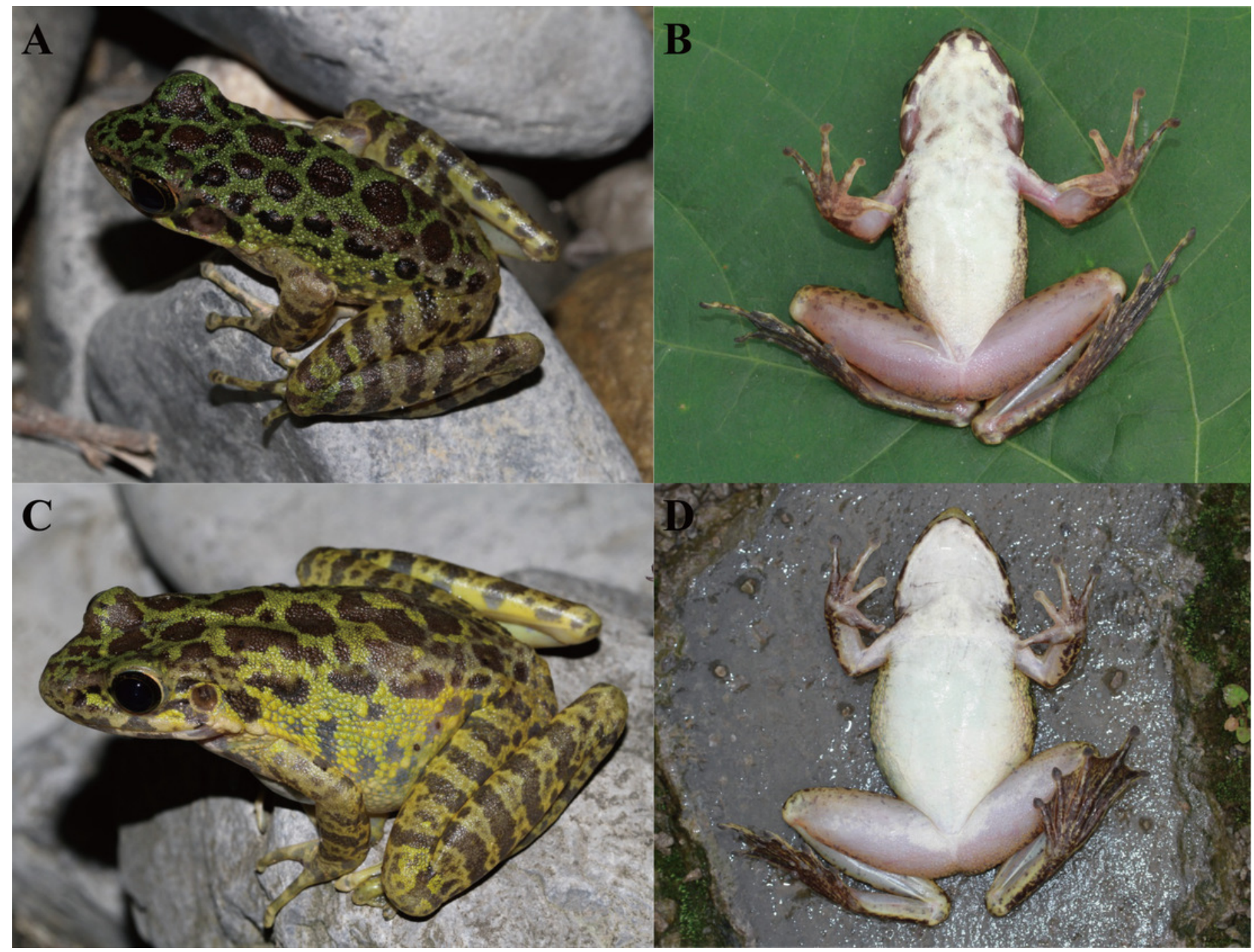




\section{Figure 7}

Color variations in Odorrana kweichowensis sp. nov..

(A) and (B), dorsolateral view and ventral view of an adult female from Jinsha County, Guizhou Province, China, respectively. (C) Dorsolateral view of a female from Meitan County, Guizhou Province, China. (D) Dorsolateral view of a female from Zheng'an County, Guizhou Province, China. Photographs by S.Z. Li.

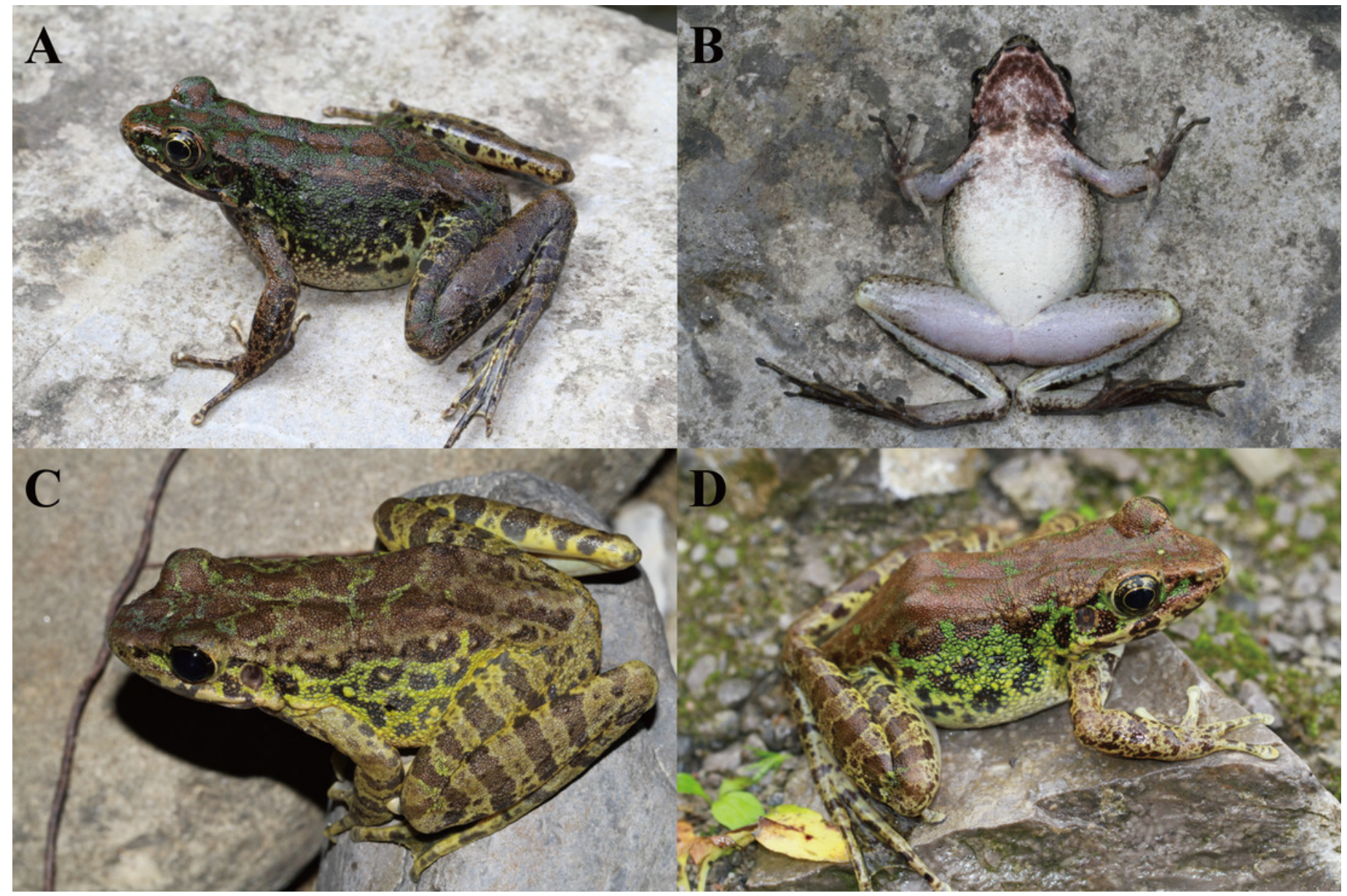


Figure 8

Skull of Odorrana kweichowensis sp. nov..

(A) Dorsal view. (B) Ventral view. 1, maxillary; 2, nasal; 3, frontoparietal; 4, pterygoid; 5, squamosal; 6 , exoccipital; 7, prootic; 8 , maxillary teeth; 9, prevomer; 10 , palatine; 11 , mandible; 12 , sphenethmoid; 13, parasphenoid; 14, columella. Drawings by S.Z. Li.

A

A
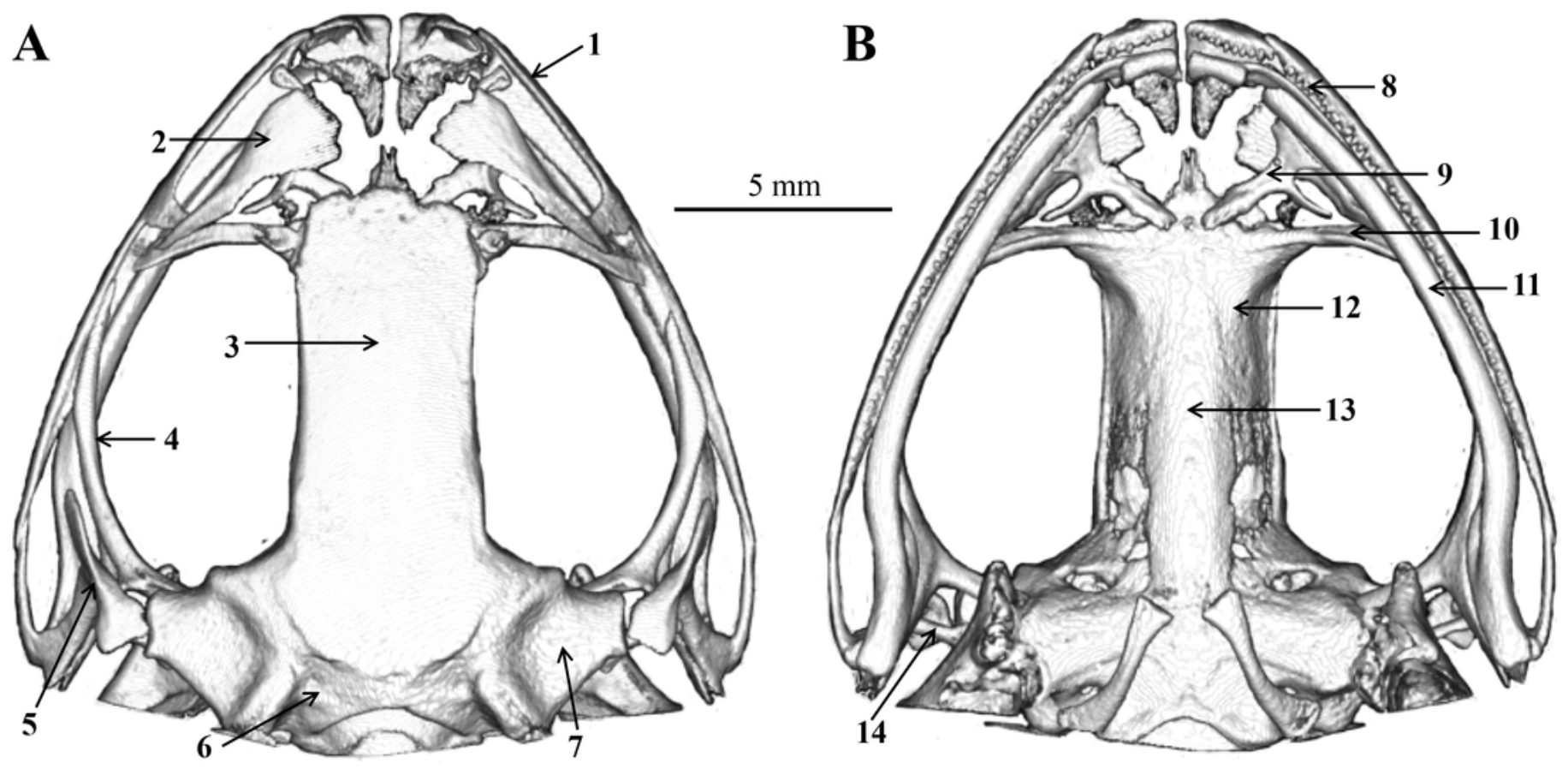


\section{Figure 9}

Tadpole of Odorrana kweichowensis sp. nov.

(A) Dorsolateral view of specimen CIBJS20171014001 in life. (B) Dorsal view of specimen CIBJS20171014001 in preservative. (C) Structure of the mouth of specimen CIBJS20171014001. 1, spiracle; 2, upper keratodonts; 3, lower keratodonts; 4, labial papillae on upper lips; 5 , labial papillae on lower lips; 6 , additional tubercles at the angles of mouth. Photographs by S.Z. Li.

*Note: Auto Gamma Correction was used for the image. This only affects the reviewing manuscript. See original source image if needed for review.

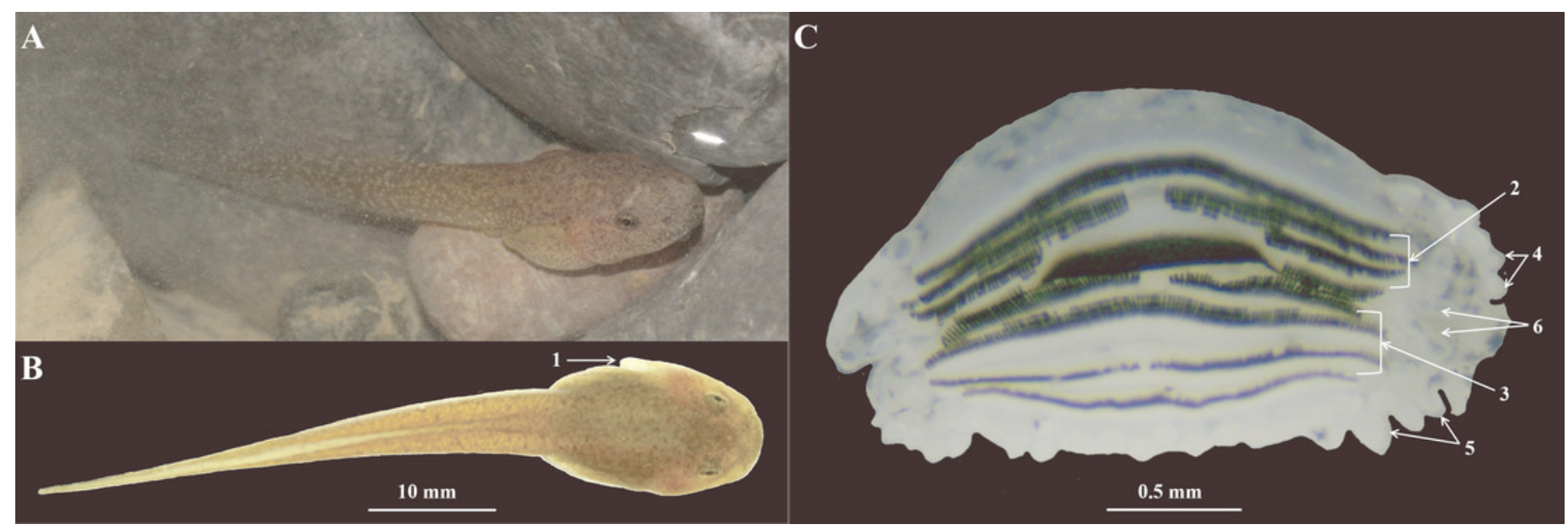




\section{Figure 10}

Habitats of Odorrana kweichowensis sp. nov..

(A) Habitats in the type locality, Lengshuihe Nature Reserve, Jinsha County, Guizhou

Province, China; insert is the photo for one pair of amplexed male (smaller) and female (larger) found on the stone in the stream. (B) Habitats in Xieba Town, Zheng'an County, Guizhou Province, China. (C) Habitats in Shilian Town, Meitan County, Guizhou Province, China. Photographs by S.Z. Li. 

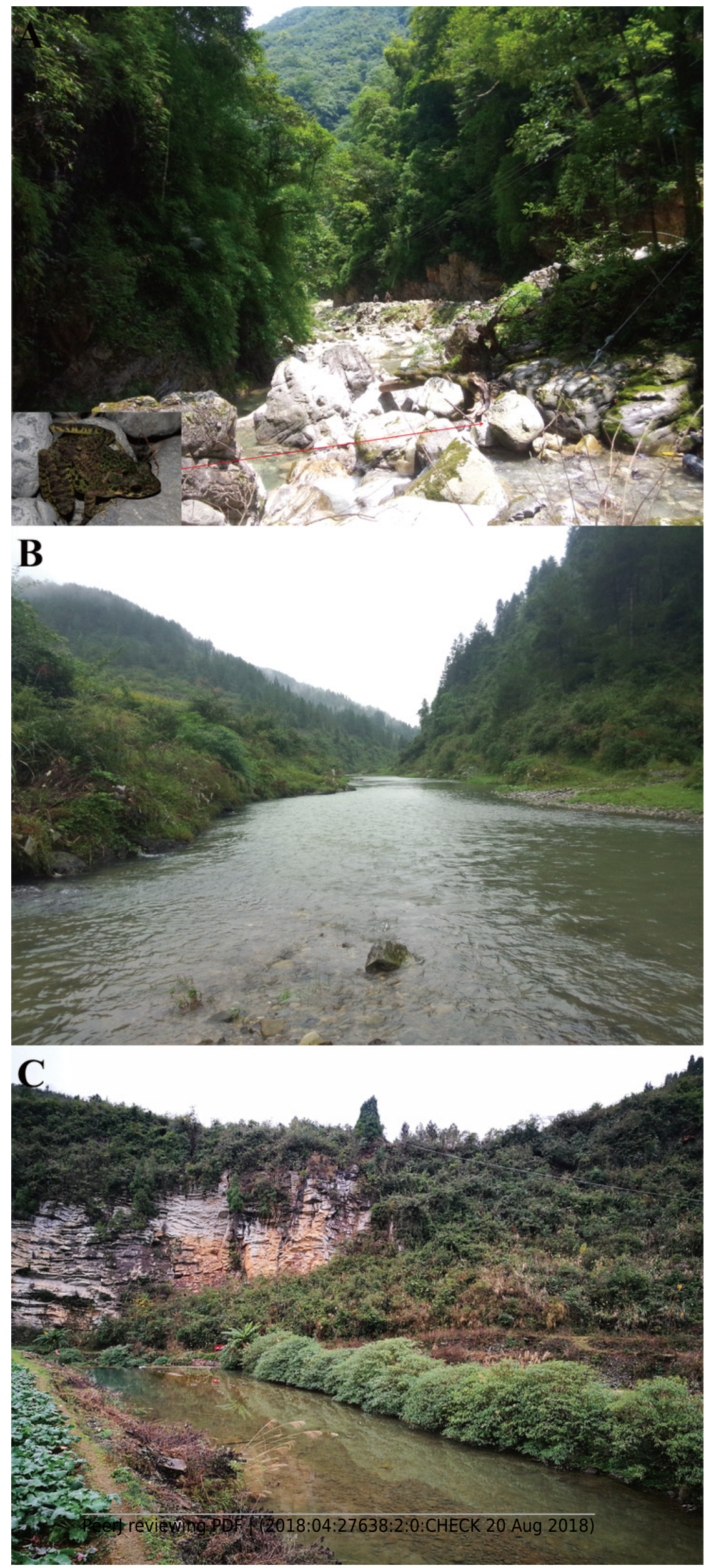